\title{
RAFAEL MITJANA Y ARDISON. ARQUITECTO MALAGUEÑO (1795-1849)
}

\author{
Francisco José Rodríguez Marín
}

\begin{abstract}
RESUMEN
Rafael Mitjana y Ardison es uno de los arquitectos malagueños menos conocidos, y a su vez afamados por su responsabilidad en la erección de un monumento de enorme presencia ciudadana como es el dedicado al general Torrijos. En este artículo se desgrana su biografía, que nos revela a un personaje inquieto, bien implantado en la sociedad de su época y cuya actividad como arquitecto fue enormemente diversificada dentro de la práctica académica y clasicista imperante en su época. Sus actividades empresariales privadas, sus aportaciones a la cartografía, a la difusión del conocimiento o al avance de la técnica, nos desvelan a un profesional de sólida formación artística a la vez que técnica que no se sustrajo a implicarse en la pujante actividad económica iniciada en Málaga a partir del primer tercio del siglo XIX.
\end{abstract}

\section{ABSTRACT}

Rafael Mitjana and Ardison is one of the less known architects from Málaga, and, on the other hand, one of the most renowned for his responsibility in the raising of the monument devoted to General Torrijos, which has an enormous presence in the city life. In this article we try to analyse his biography, which reveals a restless personality belonging to the society of his time, with an academic activity as architect very different from the classical art at that moment. His private business activities, his contribution to Cartography and diffusion of knowledge or advance in Technology reveal a professional with a form technical and artistic education, really implicated in the vigorous economic activity in Málaga during the first thirty years of the XXth century.

\section{RAFAEL MITJANA: UNA BIOGRAFÍA}

Rafael Mitjana y Ardison nació en Málaga en 1795, hijo del matrimonio integrado por D. Odon Almengol Ignacio Brunet y Mitjana -al que se conocía por el nombre abreviado de Ignacio Mitjana, haciendo prevalecer el apellido 
de su abuelo paterno, Francisco Mitjana-, de profesión comerciante ${ }^{1}$, y $\mathrm{D}^{\mathrm{a}}$. María Ardison y Rojas. El padre procedía de la localidad leridana de Seo de Urgell, mientras que la madre era de Málaga.

Durante la Guerra de Independencia Rafael Mitjana debía ser muy joven, y sin embargo combatió como subteniente de ingenieros llegando a recibir varias condecoraciones, según informaba él mismo ${ }^{2}$. Curiosamente, durante su participación en la Guerra de la Independencia fue su coronel el después general Torrijos ${ }^{3}$, a quien años más tarde rendiría homenaje póstumo con el monumento que se le dedicó en la plaza de la Merced.

En 1820 contrajo matrimonio con $\mathrm{D}^{\mathrm{a}}$. Ramona de las Doblas, malagueña, de extracción social modesta, con quien tuvo varios hijos, de los que tan solo sobrevivieron tres: Rafael, María y Francisco Mitjana de las Doblas. Por entonces era propietario de una fábrica de barajas. Rafael Mitjana enviudó en 1830 .

El 13 de diciembre de 1835, a los cuarenta años de edad, aprobó el examen de la Real Academia de Bellas Artes de San Fernando de Madrid, con el que obtuvo el título de arquitecto ${ }^{4}$. En estos años eran pocos los facultativos titulados activos en Málaga ${ }^{5}$, y esta circunstancia le permitió acceder al desempeño de varios y simultáneos cargos oficiales, como arquitecto municipal, provincial $^{6}$, del Gobierno Civil y de la Delegación de Hacienda.

Al año siguiente, en 1836, volvió a contraer matrimonio con su cuñada $\mathrm{D}^{\mathrm{a}}$. Rafaela de las Doblas, con la que tuvo también una nutrida descendencia de la que tan solo sobrevivieron hasta sobrepasar los primeros años de infancia otros tres hijos: Rafaela, Enrique y Eduardo Mitjana de las Doblas. Su

1. La profesión del padre consta en un único documento: el registro de fallecimiento de su hijo Rafael Mitjana y Ardison (A)rchivo (M)unicipal de (M)álaga, Registro de Difuntos vol. 59$60, n^{\circ} .101$

2. MATEO AVILÉS, E.: La Sociedad de Seguros contra incendios de edificios y los orígenes del Servicio de Bomberos en Málaga durante el siglo XIX, Málaga 2000, 19.

3. MORALES FOLGUERA, J.M.: Málaga en el siglo XIX, Málaga 1986, 64.

4. Archivo de la Real Academia de BB.AA. de San Fernando, Libro de ingreso de arquitectos, 154/3. Rafael Mitjana fue anotado con el número 176.

5. Baltasar Hernández le precedió en el cargo de arquitecto de la ciudad. Vid. A.M.M. Actas Capitulares vol. 234, año 1836. Otros arquitectos que coincidieron en su ejercicio profesional con Rafael Mitjana fueron Manuel de Mesa y Cirilo Salinas Pérez, así como el maestro de obras José Mapelli. Vid RODRÍGUEZ MARÍN, F.J.: Eclecticismo e historicismo en la arquitectura malagueña, Memoria de Licenciatura inédita, $\mathrm{Dpt}^{\mathrm{o}}$. de $\mathrm{H}^{\mathrm{a}}$. del Arte, UMA, 1986.

6. Hemos indagado en el Archivo Histórico de la Diputación Provincial, en el que los fondos del siglo XIX se conservan de forma parcial, y donde no ha quedado el menor rastro documental de la actividad desarrollada por el arquitecto. Corroboramos su filiación al organismo provincial por la dedicatoria del proyecto al duque de la Victoria. 
domicilio se hallaba -y lo fue hasta su muerte-, en la plaza del Marqués del Vado (actual plaza de Mitjana) $n^{\circ} .1$.

El 17 de mayo de 1838 fue nombrado arquitecto municipal, pues resultó beneficiado de una coyuntura favorable, en la que el que hasta entonces había ocupado este puesto, Cirilo Salinas Pérez, fue destituido por desobediencia al cabildo $^{7}$, y en ese preciso momento en el que era necesario levantar un plano de la Malagueta se vio en Mitjana a la persona idónea, acordándose en el mismo cabildo que destituyó a Salinas otorgarle el nombramiento ${ }^{8}$. Sin duda alguna, el plano de la ciudad que Mitjana había elaborado meses atrás y que había regalado a las corporaciones municipal y provincial, desempeñó un beneficioso papel a su favor.

En su testamento, realizado en 1846, nombraba a su entonces esposa, tutora de los hijos habidos con su matrimonio, asesorada por un grupo de personas de su confianza: D. Jerónimo y D. Miguel Gabriela, su primo, el presbítero D. José Braset y D. Juan Ruiz de la Herrán, quienes gozaban de su confianza. En caso de fallecimiento de su esposa disponía que fuese tutor de sus hijos su yerno. D. Eugenio Santamaría. Para los hijos de su primer matrimonio elegía por tutores y hasta su mayoría de edad, a los mismos que para los de sus segundas nupcias.

En 1846 Mitjana vivía en la casa de la Plaza del Marqués del Vado ${ }^{9}{ }^{\circ} .1$ con su segunda esposa, Rafaela, que tenía entonces la edad de 36 años. Rafael, hijo de su primer matrimonio, tenía 29 años y era arquitecto $^{10}$, y Francisco, de 22 años, ya ejercía como fabricante de abanicos. Los niños del segundo matrimonio, Rafaela, Eduardo y Enrique, tenían entonces 6, 4 y 8 años de edad. Convivían en el mismo domicilio María y José, dos criados. Como vecino, es decir, en otra vivienda del mismo edificio, vivían su yerno Eugenio Santamaría y su hija María, entonces de 31 años de edad ${ }^{11}$.

En diciembre de 1848 -quizás como consecuencia de la enfermedad que padecía ya en agosto-, redactó un codicilo en el que hacía referencia a una nueva propiedad, el cortijo denominado Cañaveral de los Frailes, que con su casa y almazara valoraba en 183.334 rs., que deja a su hijo mayor, Rafael, para

7. Salinas se negó a practicar unas alineaciones en una casa de la calle Carnecerías acompañado del obrero mayor, por considerar que carecía de la titulación legal que le facultaba para ello, con lo que se denigraba a la profesión, dando muestras de su talante personal y espíritu corporativista. A.M.M., legajo 1382 exp. 77.

8. A.M.M., Actas Capitulares vol. 237 fo . 145v-146, sesión 17 de mayo de 1838.

9. Era propiedad del marqués de la Puebla, a quien la tenía arrendada. A.M.M., Padrones, año 1842, f f . 296v. Agradezco la referencia a mi compañero, el pr. D. Francisco Palomo Díaz.

10. Se hallaba ausente. No se conoce obra suya en Málaga, por lo que debió ejercer en otra provincia.

11. A.M.M., Padrones, vol. 175, año 1846, cuartel $6^{\circ}, \mathrm{f}^{\mathrm{o}} .71 \mathrm{v}$. 
que la pudiese labrar, aunque recomendándole que se pusiese de acuerdo con su hermano Francisco y que la propiedad sirviese de recreo para el resto de la familia ${ }^{12}$.

Rafael Mitjana era persona religiosa que dispuso que se aplicasen por su alma 12 misas, dejando a decisión de sus albaceas la elección de la iglesia, así como el hábito con el que habían de amortajarlo y la forma de su entierro ${ }^{13}$.

El fallecimiento se produjo pronto, el 17 de enero de 1849, como consecuencia de una fiebre tifoidea y cuando tenía tan solo 54 años de edad. Este es el motivo por el cual Madoz, al referirse a la participación de Mitjana en la exposición promovida por el Liceo, le calificase como "el malogrado cuanto aventajado joven arquitecto D. Rafael Mitjana”. Las honras fúnebres se celebraron al día siguiente de su fallecimiento en la parroquia a la que pertenecía, los Santos Mártires, siendo inhumado en el nicho 843 del cementerio de San Miguel ${ }^{14}$.

Tras su fallecimiento el puesto de arquitecto municipal, que quedó vacante, pasó a ocuparlo el arquitecto José Trigueros y Trigueros, quien fue nombrado el 10 de febrero de 1849. Desde 1843 Trigueros había compartido con Mitjana esta función como arquitecto segundo, repartiéndose entre ambos la asignación ${ }^{15}$.

\section{RAFAEL MITJANA, EMPRESARIO}

Una faceta destacable y complementaria de la actividad artística de Rafael Mitjana era su aptitud para los negocios y para incrementar su patrimonio. En 1820, año en el que realizó un balance de bienes con motivo de contraer su primer matrimonio, poseía un capital de 107.000 reales de vellón invertidos en una fábrica de barajas y los materiales acopiados en stock, como maderas y papel.

12. (A)rchivo (H)histórico (P)rovincial de (M)álaga, Protocolos, legajo 4110 fo . 1015-1016v. Agradezco a $\mathrm{D}^{\mathrm{a}}$. Esther Cruces Blanco, directora de este archivo, el conocimiento de esta documentación. La finca El Cañaveral de los Frailes había pertenecido al convento dominico de Málaga, que a mediados del siglo XVII ya había iniciado su parcelación y venta. Vid. MUÑOZ MARÍN, M.: Contribución al conocimiento de la historia de los espacios utilizados para el crecimiento superficial de la ciudad de Málaga durante el siglo XIX, Tesis doctoral inédita, Dpto. de $\mathrm{H}^{\mathrm{a}}$ Moderna y Contemporánea, Universidad de Málaga, 2003, 925. Una publicación reciente confunde este cortijo con un convento que nunca fue.

13. A.H.P.M., Protocolos, Escribanía de Joaquín Ruiz Romero, legajo 4107, fo. 574-580s. Agradezco la referencia a $\mathrm{D}^{\mathrm{a}}$. Esther Cruces.

14. A.M.M., Órdenes de Sepelio, legajo 1446. Ascendió el abono de sus derechos de inhumación a 130 reales.

15. RODRÍGUEZ MARÍN, F.J.: "El arquitecto José Trigueros: entre el clasicismo decimonónico y la utopía", Boletín de Arte 9, 1988, 238. 


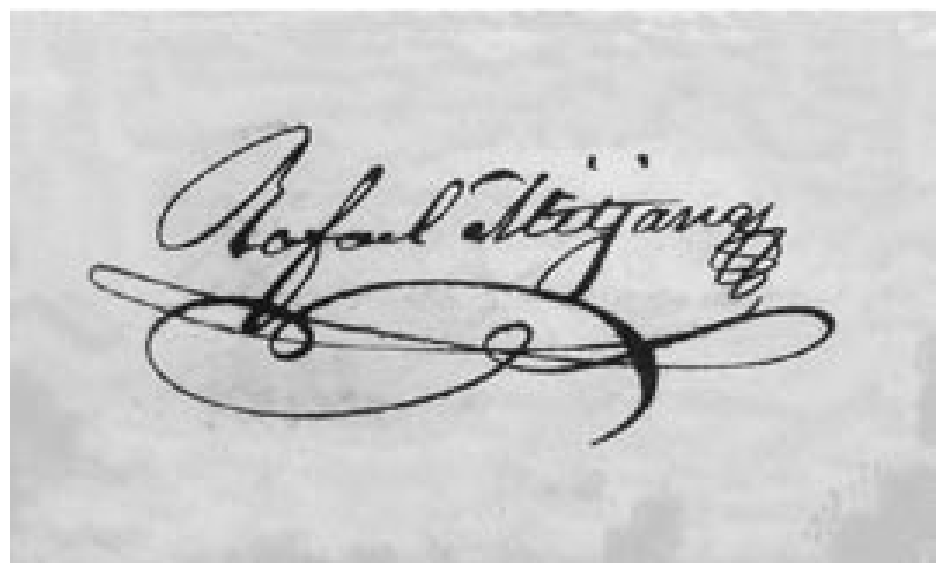

1. Firma autógrafa de Rafael Mitjana

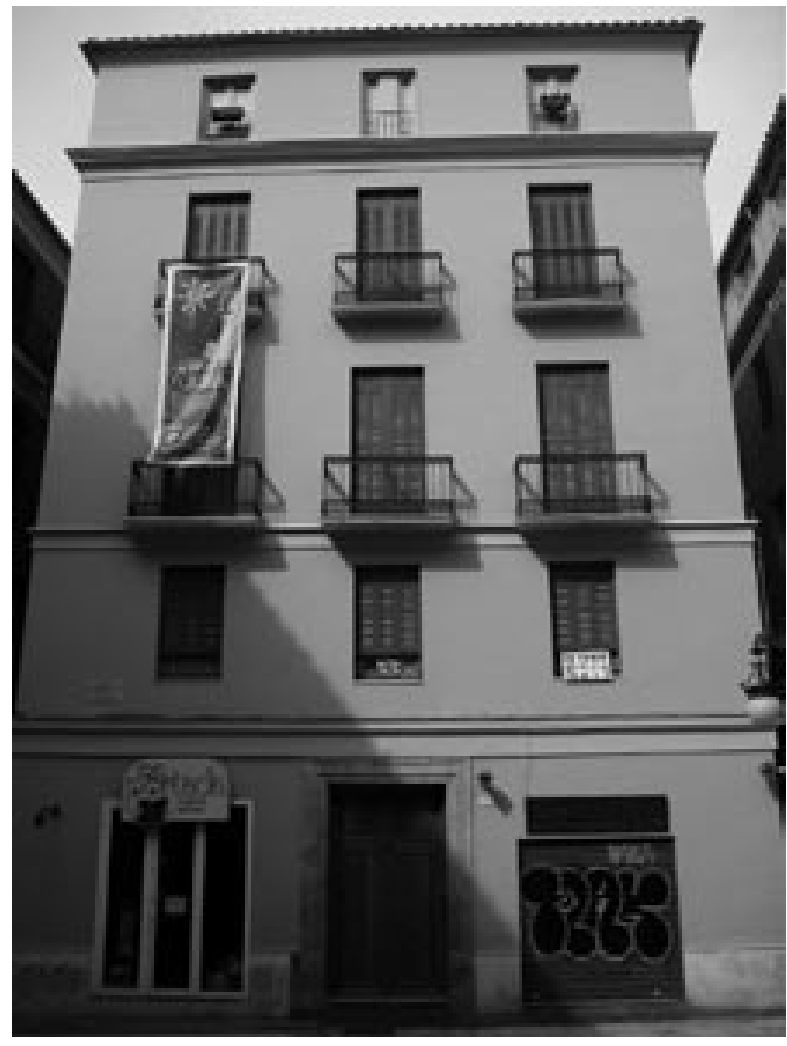

2. Domicilio familiar en la plaza de Mitjana 


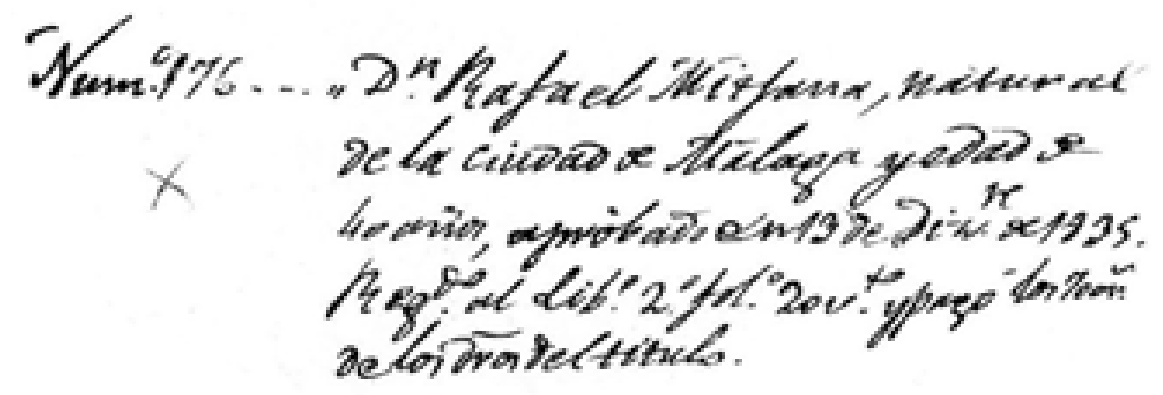

3. Anotación de obtención del título de arquitecto (A.A.S,F.)

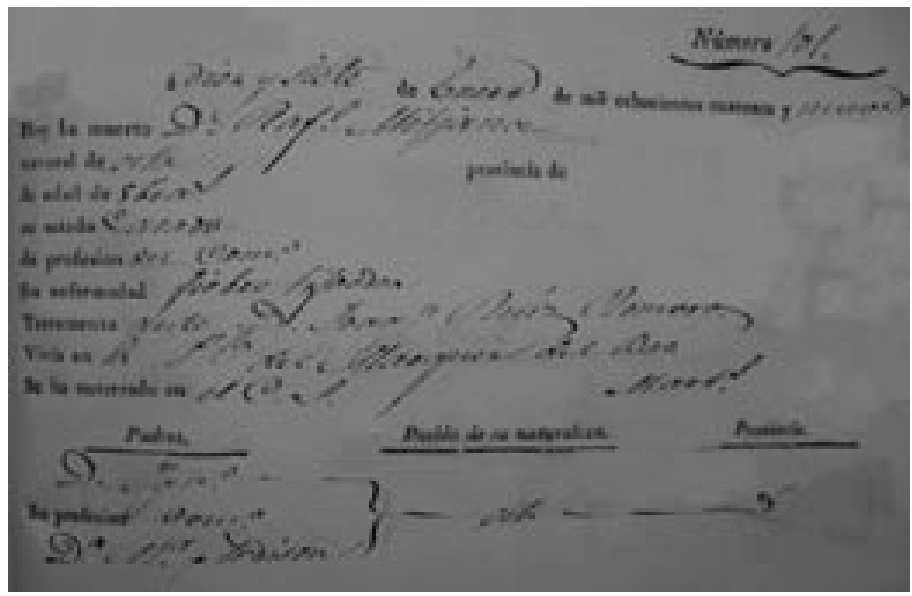

4. Registro de defunción de Rafael Mitjana (A.M.M.)

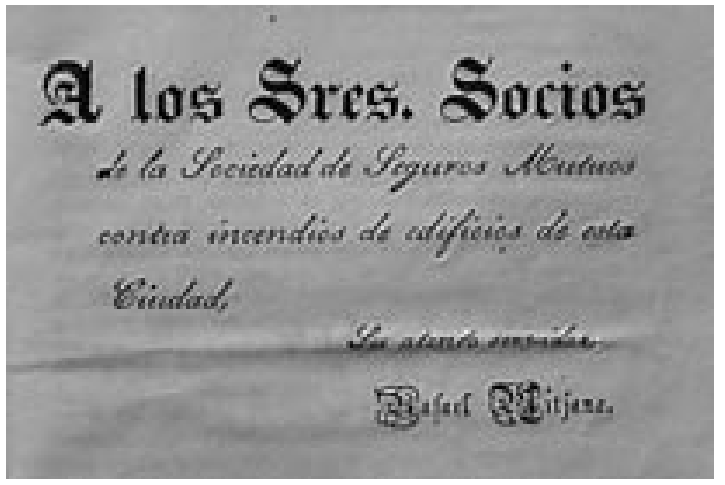

5. Dedicatoria del opúsculo sobre la Mutualidad de Incendios (A.D.E.) 
Parte de este capital provenía de la herencia recibida de sus padres en el momento de alcanzar la mayoría de edad, aunque de la casa familiar, ubicada en la calle San Bernardo el Viejo y que habitaban sus hermanos, no recibió nada.

En el momento de contraer su segundo matrimonio su capital ascendía a 236.000 reales que invirtió en la compra del Lagar Grande llamado Ibáñez, en el partido de Ávila, y una casa en la calle Canasteros de la capital.

Ambas fincas fueron posteriormente vendidas para con su importe adquirir una fábrica de abanicos (era también taller de litografías), actividad que consideraba más próspera. Esta fábrica la adquirió a D. Jerónimo Gabrielis en 1837 por 184.340 reales de vellón. Llama la atención que en algunos de los padrones realizados en los últimos meses de su vida se declarase como comerciante, cuando ya había alcanzado notoriedad y merecido reconocimiento como arquitecto.

En consonancia con las confianzas depositadas en aspectos personales de su vida, en su testamento nombró contadores y partidores de sus bienes a las mismas personas elegidas como tutores de sus hijos. Asimismo, con la única excepción de D. Juan Ruiz de la Herrán, nombraba albaceas testamentarios a las mismas personas además de a su hijo político, D. Eugenio Santamaría y a D. Diego Ramírez. Consciente de que tras su muerte la herencia de los hijos de su primer matrimonio sería inferior a la de los segundos, dispuso que el tercio y quinto de libre disposición se asignase a los hijos del primer matrimonio con el objeto de igualar el montante de sus herencias.

Ya hemos mencionado que al final de su vida incrementó su patrimonio con una nueva finca que también destinó, preferentemente, a los hijos de su primer matrimonio.

Uno de ellos, Francisco Mitjana de las Doblas, mantuvo la estela empresarial iniciada por su padre. En 1861 aún mantenía la fábrica de abanicos -que también elaboraba litografías-, en el edificio familiar de la plaza del Marqués del Vado, que ya para entonces había pasado a denominarse plaza de Mitja$\mathrm{na}^{16}$, mantenida en sociedad comandita con Rafael Santamaría ${ }^{17}$ y para la que trabajaron numerosos artistas y grabadores.

\section{RAFAEL MITJANA, ARQUITECTO}

\subsection{Arquitectura doméstica}

En relación con la arquitectura doméstica se documenta como el 25 de abril de 1839 efectuó la tasación de varias viviendas, y el 20 de agosto de 
este mismo año realizó, conjuntamente con el arquitecto Manuel de Mesa ${ }^{18}$, la tasación de una casa de la calle Almacenes, propiedad que fue de Manuel Domingo Sáenz, en la cantidad de 41.988 reales $^{19}$. En 1842 fue uno de los tasadores de la finca cortijo de Cabello ${ }^{20}$.

También en 1839, y en el ejercicio de su función como arquitecto municipal, realizó un informe sobre el estado de la capilla del cementerio público, que mostraba serios síntomas de deterioro pese a que fue construida tan solo dos años antes. El ayuntamiento resolvió que la inspección la realizase Mitjana junto al arquitecto Cirilo Salinas Pérez, con el que demostró falta de entendimiento: Mitjana, más riguroso, exigió el montaje de un andamio para poder dictaminar acerca de la cúpula, mientras que Salinas concluyó que la situación no era tan preocupante como pareciera. Finalmente la obra de restauración quedó aplazada ante la falta de presupuesto ${ }^{21}$.

De las construcciones domesticas de promoción privada ejecutadas por Mitjana ninguna de ellas se ha conservado y las conocemos por la documentación que generaron al tramitarse su construcción. La primera, en la plaza de San Francisco, la analizamos en el apartado que dedicamos a la actuación del arquitecto sobre el solar de este convento desamortizado.

La segunda se emplazaba en la calle Salvago, un modesta edificación de bajo más una planta con vanos adintelados en forma de balcones en la planta superior y ventanas enrejadas en el bajo. El zócalo, las pilastras y el remate de fachada ocultando las vertientes del tejado son los únicos elementos compositivos que pueden reseñarse ${ }^{22}$. El de la calle Salinas (plazuela del Desengaño), era de mayor porte, con bajo, dos plantas y azotea, y presentaba un esquema compositivo similar a las otras dos obras domésticas de Mitjana, articulando pilastras, cornisas como divisorias horizontales de las plantas y un pretil reforzado con pilares en la azotea ${ }^{23}$.

Otra actuación, ya como arquitecto municipal, fue la realizada sobre el convento franciscano de San Pedro Alcántara. El edificio, abandonado su uso religioso desde 1810, llegó al primer tercio del siglo XIX parcialmente demolido ${ }^{24}$

18. Manuel de Mesa presentó su título de arquitecto para que la corporación municipal le reconociera como tal el 20 de febrero de 1838. Vid. A.M.M., Actas Capitulares vol. $238 \mathrm{f}^{\mathrm{o}} .59$.

19. LLORDÉN, P.A. (O.S.A.): Arquitectos y canteros malagueños, Ávila 1962, 230.

20. Vid. MUÑOZ MARÍN, M.: op. cit., 917.

21. DELGADO BAEZA, M.: La recuperación del patrimonio histórico-artístico de Málaga del siglo XIX: el arquitecto Cirilo Salinas Pérez, Memoria de Licenciatura inédita, Dpt ${ }^{\circ}$. de $H^{\mathrm{a}}$. del Arte de la UMA, 1986, 48.

22. A.M.M., legajo 1382 expediente 104

23. Ibídem, expediente 101

24. Los maderos aprovechados del derribo del convento de San Pedro se estaban utilizando en las obras de conversión del convento de la Victoria en hospital. A.M.M., Actas Capitulares vol. $238, \mathrm{f}^{\mathrm{o}} .63 \mathrm{v}-64$. 


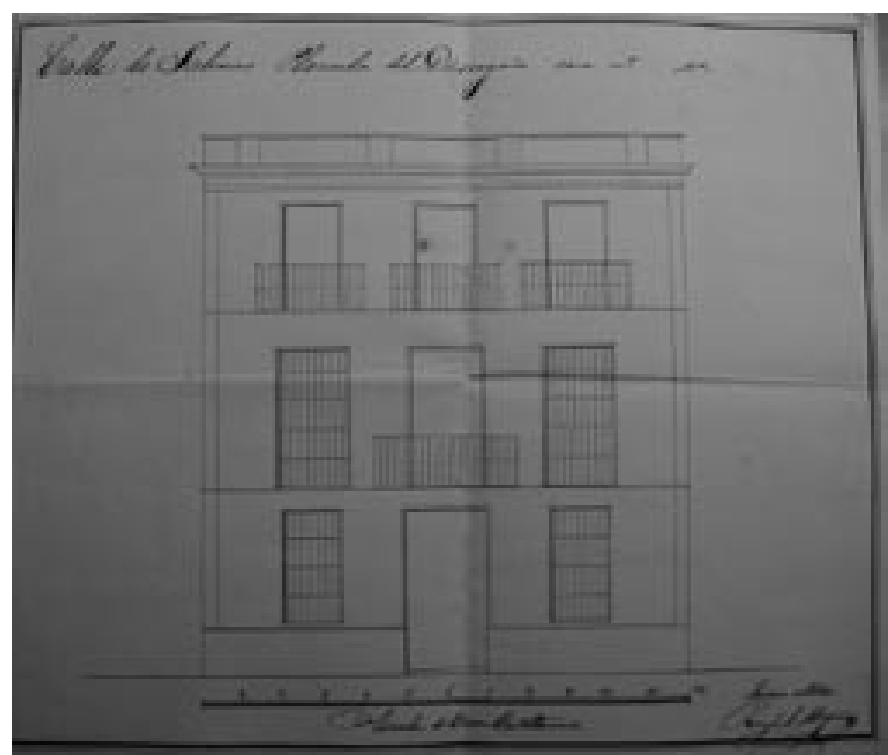

6. Proyecto de casa en calle Salinas (A.M.M.)

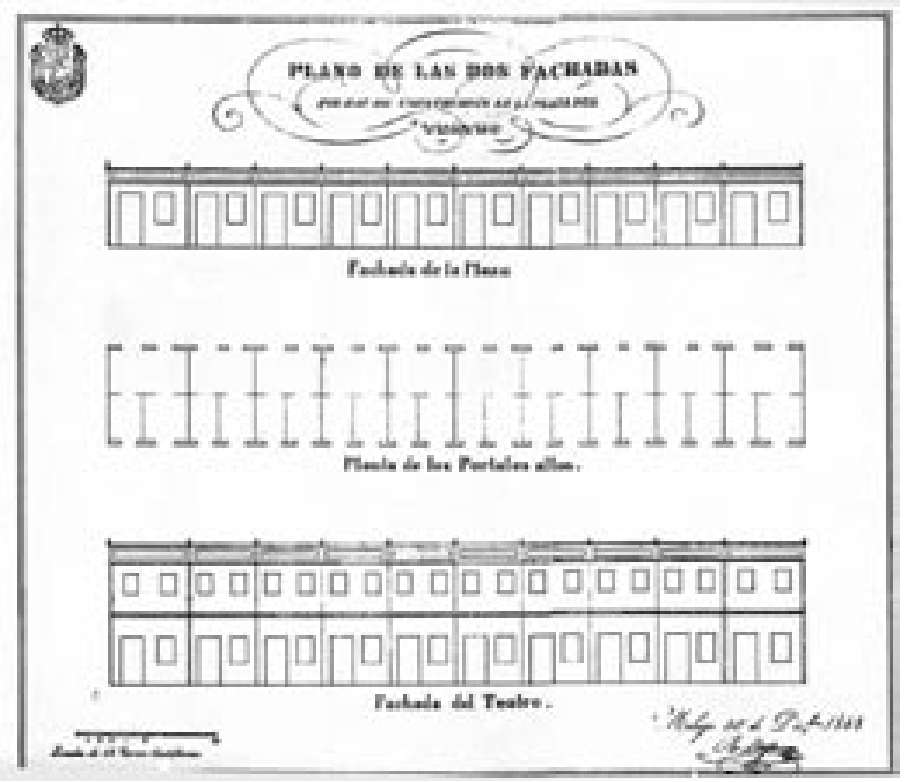

7. Proyecto de mercado sobre el solar del convento de San Pedro Alcántara (A.M.M.) 


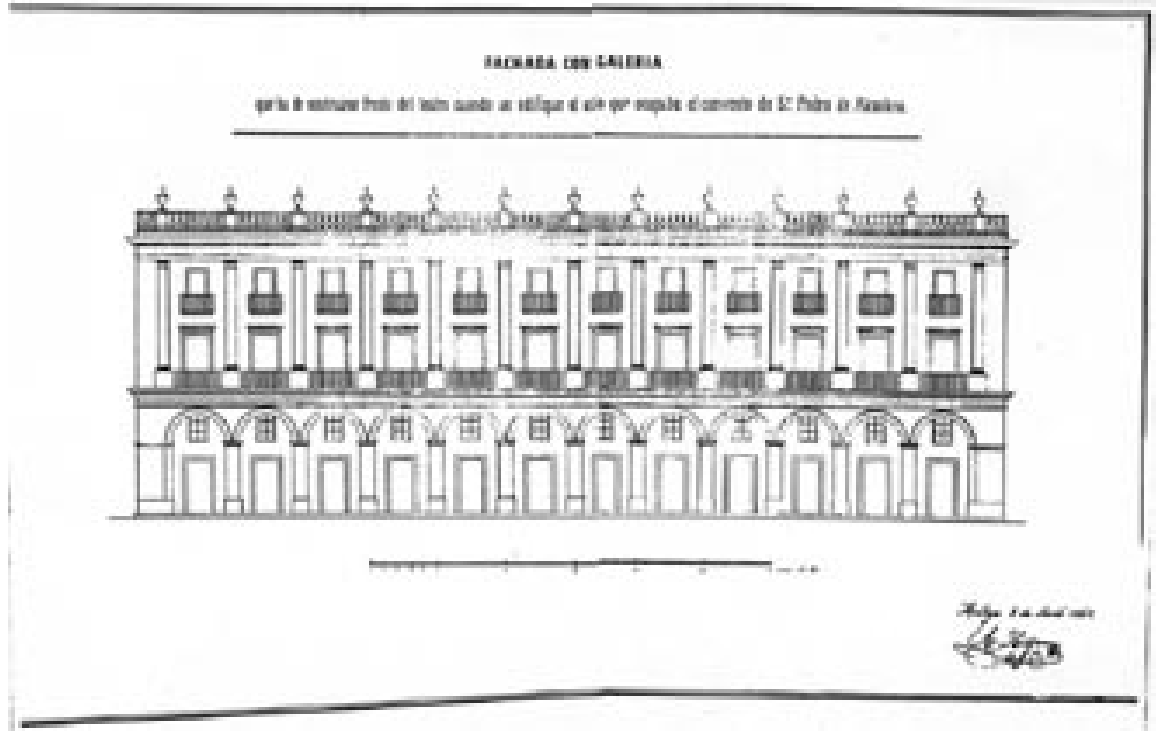

8. Proyecto de edificios de viviendas en la plaza del Teatro (no ejecutado) (A.M.M.)

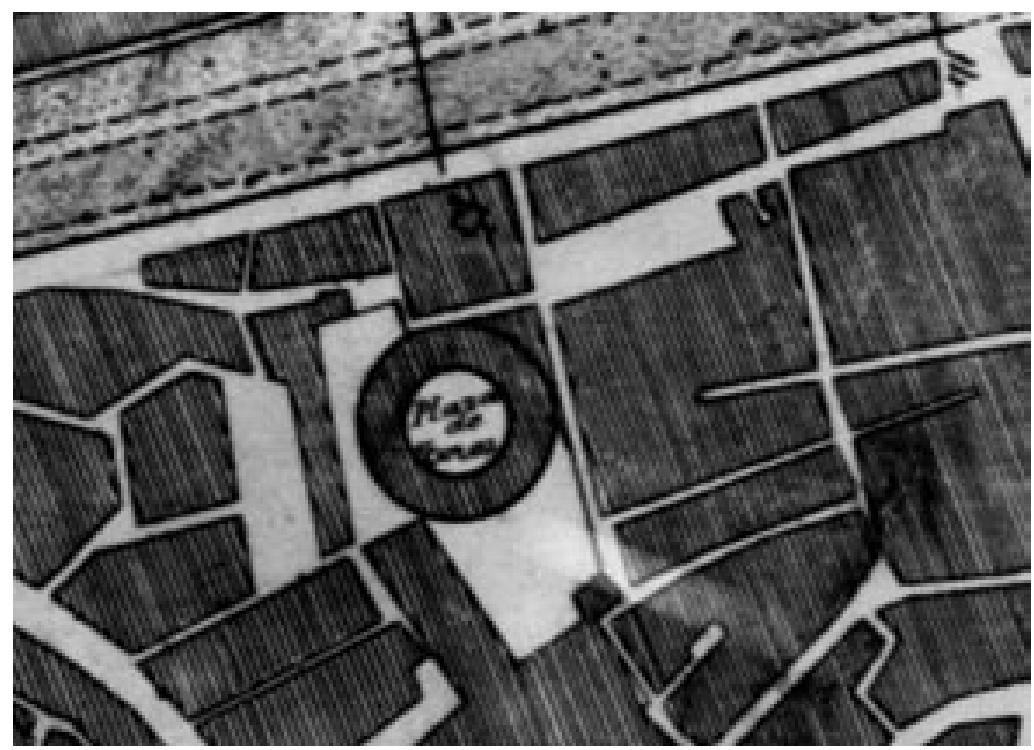

9. Representación de la plaza de toros de Álvarez en el plano de Málaga de Pedro Antonio de Mesa, 1861 
y con un estado de deterioro notable. En 1839 se solicitó de Mitjana que redactase un proyecto de mercado, del que la ciudad se hallaba muy necesitada, pero como en otras ocasiones la situación financiera resultó determinante y la actuación quedó reducida a la construcción de un muro de contención y la habilitación de ocho bóvedas del exconvento como portales para la venta, pero en 1845 el mismo arquitecto dictaminó que era necesario demoler la fábrica ante su estado ruinoso. En 1848, efectuada ya la demolición total, realizaron mediciones y replanteos del solar tanto Cirilo Salinas como Mitjana, sin que sus apreciaciones, nuevamente, volviesen a coincidir.

El proyecto de mercado fue elaborado por Mitjana con gran sencillez: tan solo la sucesión de portales y la escasa fachada del edificio, de doble planta, nos recordaba que nos hallábamos ante un edificio de abastos, debido a su marcado aspecto doméstico. Pero nadie pujó en la subasta celebrada el 16 de junio de 1848 para adjudicar la obra y sin embargo llegó una propuesta de compra de una superficie mayor por parte de la poderosa familia Larios, quienes acompañaban su solicitud de los planos para la construcción de un gran edificio proyectado por el mismo Mitjana. Aparece así la sombra de una posible connivencia entre el arquitecto y la poderosa burguesía industrial.

El edificio proyectado por Mitjana, de grandes proporciones, venía a ocupar la mayor parte del solar que fue convento, con su fachada principal hacia la plaza del Teatro y la posterior hacia la actual plaza de San Pedro Alcántara, que ocupa lo que fue compás conventual. El inmueble, de estilo neoclásico, presentaba como novedad una galería cubierta con arcos de medio punto en el bajo, muy útil porque se hallaba frente al Teatro Principal y facilitaría la dispersión de la multitud los días de función. Las dos plantas superiores mostraban pilastras de orden gigante entre la regular sucesión de balcones, coronando la fachada el pretil de la azotea en forma de balaustrada y pilares rematados con jarrones de cerámica.

Sin embargo, en 1851, a la hora de edificar lo proyectado, Mitjana ya había fallecido, y los Larios presentaron nuevos planos, esta vez elaborados por el maestro de obras Diego Clavero y Zafra, que tras concensuar con el Ayuntamiento la apertura de una calle intermedia como compensación por la eliminación de los soportales, son los que finalmente se construyeron y hoy, con algunas transformaciones, aún persisten ${ }^{25}$.

También en 1840 presentó Mitjana el plano para una casa en la calle Salinas, en la plazuela del Desengaño, de bajo y dos plantas de altura ${ }^{26}$, con regular disposición de huecos pero cuya tipología de herrajes, incluyendo los

25. A.M.M. legajo 1223, legajo 1263 expediente 106 y Actas Capitulares vol. 247 f . 56, 56v., $70,105 v$ y 106.

26. A.M.M., legajo 1382 exp. 101. 
cierros verticales de la planta principal, aún conserva resabios heredados de la arquitectura tardobarroca o de transición al neoclasicismo. Esta vivienda no se ha conservado, pues esta zona experimentó una profunda transformación con la apertura de la calle Larios a finales del siglo XIX.

La liberación de suelo tras la desamortización de conventos fue una coyuntura que proporcionó oportunidades y trabajo a los arquitectos. Las extensas huertas del convento de la Victoria se urbanizaron a partir de 1843 y ello permitió a Mitjana a proyectar algunas casas en el inicio del compás ${ }^{27}$.

Una parcela profesional menos conocida es la que se deriva de su función como arquitecto municipal desde mayo de 1838 cuando se le nombra y hasta 1849, año de su fallecimiento. Estas actuaciones resultan menos espectaculares aunque no menos necesarias en una ciudad que comenzaba a renovarse tras el largo periodo de continuismo del barroco, tales como las denuncias de obras ilegales o declaraciones de ruina ${ }^{28}$. Asimismo, al marcar las alineaciones para nuevas edificaciones contribuyó a regularizar el entramado urbano, actuando en calles como Espartería, Peña, Concepción o Don Iñigo.

\subsection{Hidráulica y obras públicas}

Otras de las funciones desempeñadas por Mitjana como arquitecto municipal era la de ocuparse del abastecimiento de agua desde el fallecimiento de Cristóbal Ramírez, quien había sido fontanero mayor, y hasta que fue nombrado para este puesto al maestro Diego Clavero. Esta era una tarea que daba numerosos problemas por la deficiente infraestructura de la que se disponía, pero cuya perentoriedad obligaba a realizar reparaciones casi continuas para no dejar desabastecida a una población que dependía de la red pública. La conducción municipal transcurría embutida en la muralla y junto al hospital de las Inválidas, situado al final de la calle Granada, donde se ubicaba una alcubilla en este ángulo de la plaza de la Merced. En 1848 se padecía una doble problemática: en la conducción municipal se producían cortes de suministro por la escasez de su caudal, estimado en 50 pajas frente a las $183 \frac{1}{2} 2$ que se estimaban necesarias para surtir a las fuentes públicas, hospitales, conventos y casas privadas.

A escasa distancia se emplazaba una segunda alcubilla, ésta perteneciente al acueducto de San Telmo, que sin embargo derramaba agua debido a que los limos obstruían las cañerías.

27. MORALES FOLGUERA, J.M.: op. cit., 137.

28. Como ejemplo podemos mencionar la denuncia de la casa de calle Comedias $\mathrm{n}^{\circ} .2$ por obras sin permiso (año 1840), la denuncia por ruina de las casas de la plaza de la Constitución $n^{\circ}$. 9, 11 y 12 (año 1840), o la también declaración de ruina, previa inspección, del Cobertizo de Carnecerías (año 1841). Vid. A.M.M., legajo 1382 exp. 90, 82 y 118. 


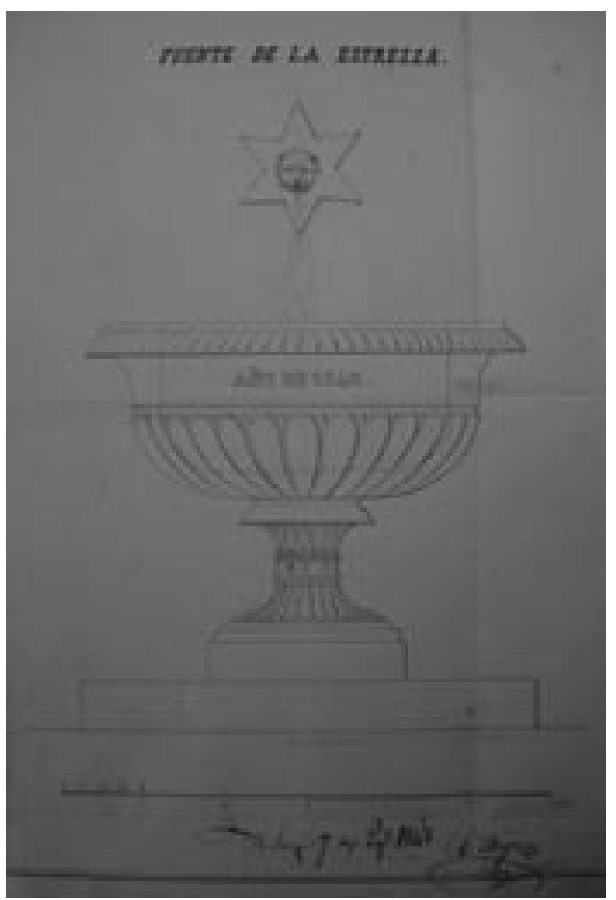

10. Proyecto para la fuente de la Estrella (A.M.M.)

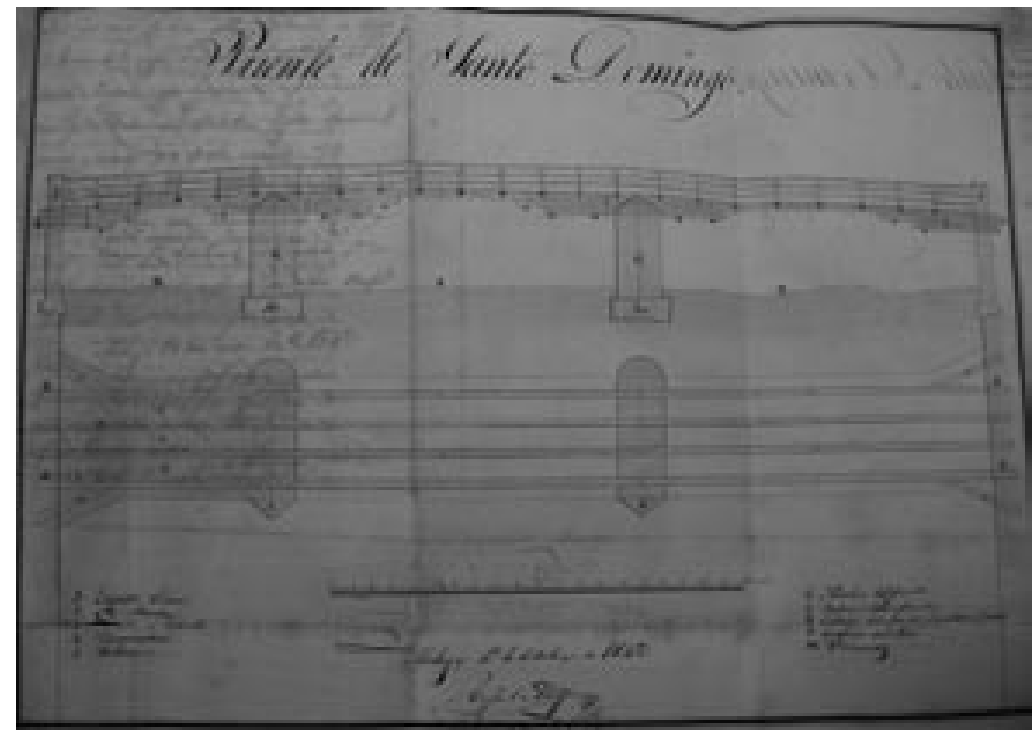

11. Proyecto de puente sobre el Guadalmedina (no ejecutado) (A.M.M.) 


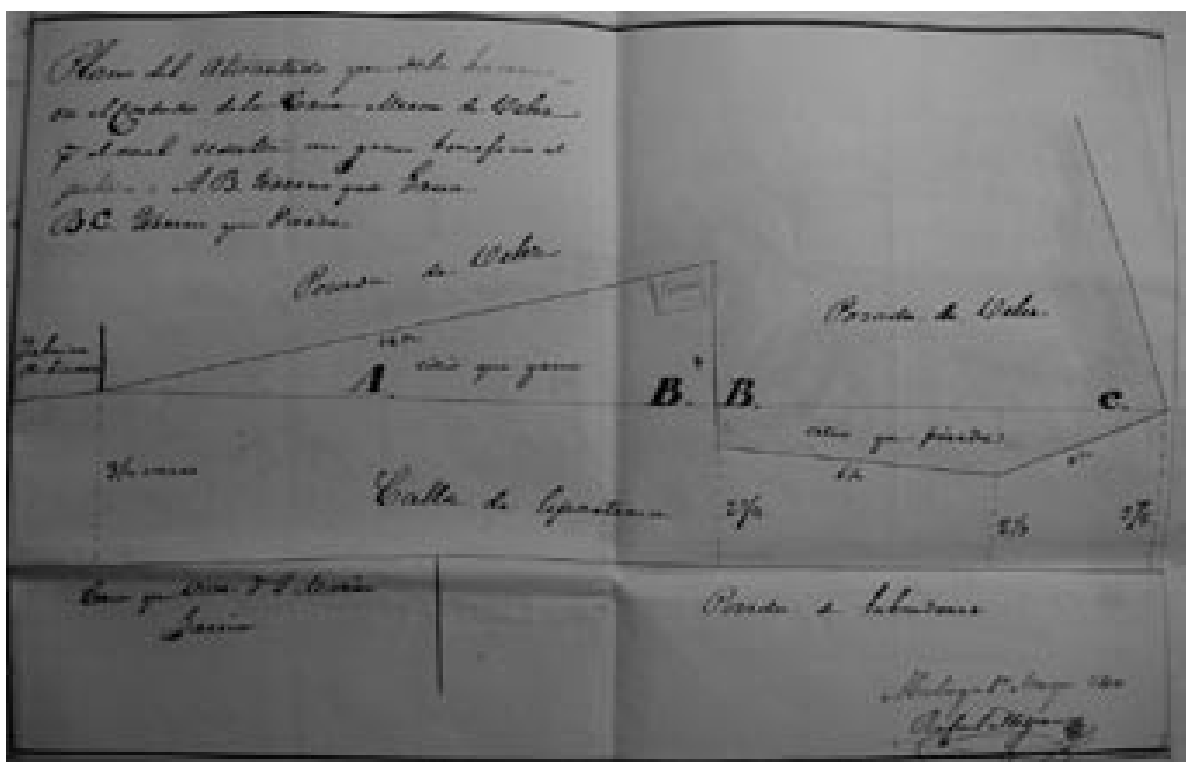

12. Rectificación de alineaciones en calle Espartería (A.M.M.)

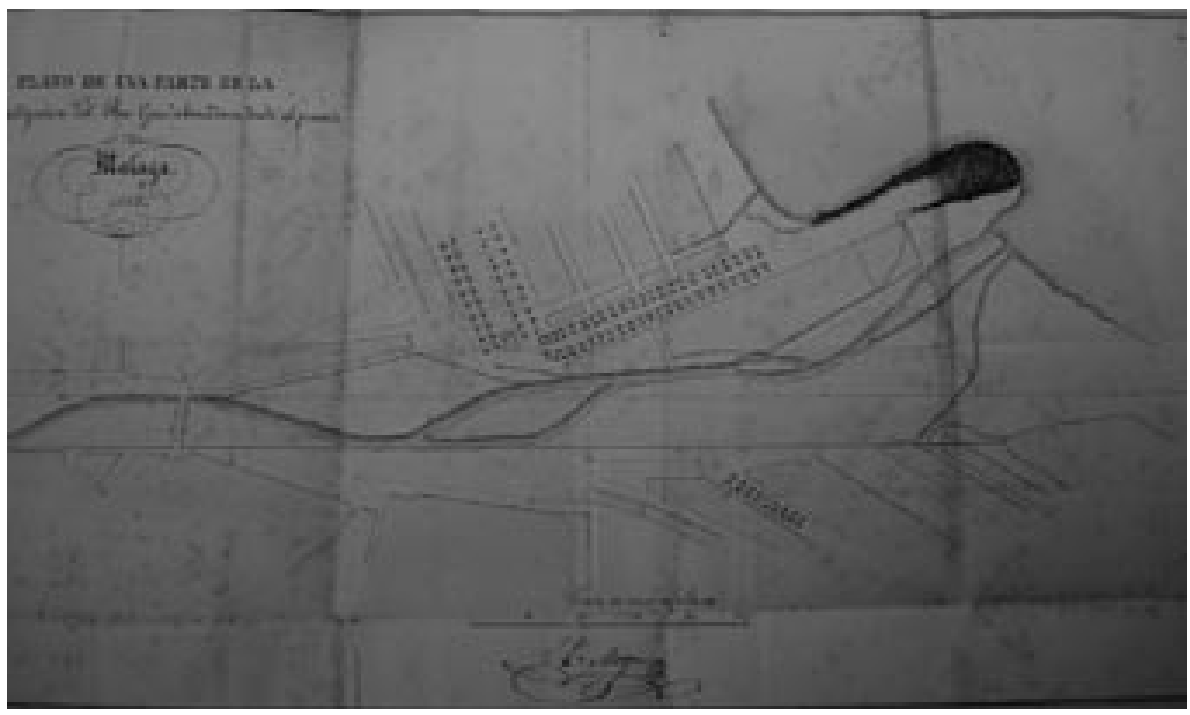

13. Proyecto de encauzamiento del Guadalmedina (A.M.M.) 
Mitjana concibió un proyecto que consistía en comunicar ambas alcubillas para que se suministrasen agua mutuamente, interponiendo entre ellas una cañería con llave doble y un novedoso dispositivo para filtrar en el lugar ocupado por una pequeña capilla dedicada Jesús Nazareno. La actuación se completaba con la construcción de una fuente -denominada de La Estrella-, adosada a la alcubilla de San Telmo, realizada con un pilar de mármol blanco sobre dos gradas. Como era común en la época se planteó aprovechar materiales procedentes de la fuente de Puerta del Mar, y aún así se presupuestó su ejecución en 2.000 rs. La fuente ofrecía un elegante aspecto, con un gran vaso avenerado al que vertía una cabeza de león inscrita en una estrella que daba nombre a la fuente. La realización de la obra fue aprobada el 22 de agosto de 1848, aunque en su transcurso enfermó Rafael Mitjana deteniendo la obra y obligando a la intervención del arquitecto José Trigueros, quien reformó el presupuesto de Mitjana, autor -no obstante-, del diseño de la fuente ${ }^{29}$.

Otra actuación dentro de este campo fue su proyecto de traslado de una fuente pública desde la plaza de la Alcazaba al lateral de la Aduana, fechado en marzo de $1848^{30}$.

El Guadalmedina, eterno problema de la ciudad por la incomunicación que causaba entre las zonas Este y Oeste de la ciudad, así como por sus frecuentes riadas e inundaciones, fue otro de los asuntos que entraron dentro de sus competencias como arquitecto municipal. En 1842 redactó un proyecto de puente para ubicar a la altura del convento de Santo Domingo, donde ya existía otro anterior no muy robusto y que debía hallarse en mal estado. El presupuesto para su ejecución ascendía a 19.976 rs., pues tampoco suponía una obra excesivamente ambiciosa, sino prácticamente una pasarela peatonal realizada con tablones de madera sobre dos únicos apoyos de fábrica. Aún así la obra no llegó a realizarse. En 1845 elaboró un proyecto para el encauzamiento del río, hasta entonces inexistente ${ }^{31}$.

\subsection{Investigación y patrimonio}

Las actuaciones profesionales de Mitjana en sus no muchos años de vida activa son muy diversas. Junto al proyecto de monumento a Torrijos, la otra actuación por la que se le conoce es por la edición de un libro singular, explicable por el interés que en esta época despertaba toda la arqueología en general

29. A.M.M., legajo 1379 expediente 51

30. A.M.M., legajo 1376 expediente 50

31. A.M.M. legajo 1-C expedientes 1 y 2. Recogidos en BARRIONUEVO SERRANO, R. y MAIRAL JIMÉNEZ, C.: Mapas, planos y dibujos del Archivo Municipal I, Málaga 2007 (en prensa). 
dentro de los círculos eruditos. Su contraportada nos informa de que su origen se encuentra en un discurso pronunciado el 20 de noviembre de 1847 ante la Real Academia de BB.AA. de San Fernando -la misma que le otorgó su título de arquitecto-, y se identifica como arquitecto municipal de Málaga y miembro de la Comisión de Monumentos Artísticos e Históricos de la provincia. La obra fue publicada este mismo año en una imprenta de la ciudad de Málaga, la de José Martínez Aguilar, con el título de Memoria sobre el templo druida hallado en las cercanías de la ciudad de Antequera, provincia de Málaga ${ }^{32}$.

El objeto de su investigación es el sepulcro megalítico de corredor denominado popularmente "Cueva" de Menga, notable ejemplo de arquitectura calcolítica que por su excepcionalidad y cercanía a otros edificios semejantes ha obtenido la consideración de patrimonio cultural de la humanidad por parte de UNESCO.

Pero cuando Mitjana lo estudió se hallaba en una situación muy distinta. En su prólogo nos informa que se hallaba inmerso en una laboriosa tarea: confeccionar un plano provincial que de haberse concluido habría venido a completar su aportación a la cartografía de la ciudad realizada casi diez años atrás. Fue en la realización del trabajo de campo destinado a este cometido cuando se topó con esta impresionante arquitectura, que halló casi cegada por tierras y conocida en la localidad como Cueva de Mengal $^{33}$. Desde el 17 de abril de 1842, que fue cuando lo contempló por vez primera, hasta la fecha de edición del opúsculo, confesó haber visitado el monumento en 25 ocasiones, consciente de su importancia, hasta entonces no reconocida. Mitjana mandó limpiar el monumento y proteger su entrada con una verja.

En las conclusiones justifica su atrevimiento: "escribo como arquitecto y no como historiador ni como erudito" 34 . En efecto, aunque en su larga disertación histórica acierta al considerar el carácter sagrado del recinto, y en mencionar otros ejemplos coetáneos de menhires y dólmenes de España, Portugal, Francia y otros lugares, erró al relacionar su autoría con la cultura prehispánica céltica, a su vez identificada con el pueblo Túrdulo, al que ubicó en la Serranía de Ronda. También acertó al considerar la naturaleza artificial del túmulo que protege la galería dolménica antequerana, aunque el nombre de "Mengal" lo hace derivar etimológicamente de un vocablo celta, "Men-Lac' h", que traduce como "piedra sagrada", pues con ello corroboraba su clasificación.

32. Agradezco a $\mathrm{D}^{\mathrm{a}}$. $\mathrm{M}^{\mathrm{a}}$. Pepa Lara, directora del Archivo Municipal, sus facilidades para consultar esta obra, y otras para la elaboración del presente trabajo.

33. Parece ser que se trata de una deformación fonética de "Cueva de Dominga", la última moradora que la utilizó como vivienda. Posteriormente derivó en "Menga", que es como hoy se la conoce.

34. MITJANA, R.: Memoria sobre el templo druida hallado en las cercanías de la ciudad de Antequera, Málaga 1847, 19. 
Pese a su error interpretativo Mitjana realizó una gran aportación con los levantamientos de planta y sección que dibujó -los primeros de este edificio que se realizaron-, de las reproducciones de otros monumentos megalíticos, y de las mediciones y descripciones del monumento, del que llegó a afirmar que los tres soportes verticales intermedios habían perdido recalzo y que por tanto podrían ser eliminados, pues nada sustentaban. Estuvo Mitjana particularmente atinado al resaltar la orientación del monumento hacia Oriente como algo pretendido y no casual ${ }^{35}$, llegando incluso a concretar la procedencia de los grandes bloques calizos en las canteras del cerro del Calvario, que distaba unas 1.000 varas de la construcción ${ }^{36}$.

La publicación de Mitjana, aún con sus errores de clasificación, fue oportuna y contribuyó en gran medida a difundir y valorar el monumento, y puede considerarse una de las primeras acciones en defensa del patrimonio arquitectónico de la provincia ${ }^{37}$, anterior incluso a la creación de la academia local de Bellas Artes.

\section{RAFAEL MITJANA Y LA ARQUITECTURA MONUMENTAL}

En su práctica profesional como arquitecto, tanto en la edificada como en la proyectiva teórica, siempre mostró predilección, como era habitual en su época, por el arte clásico. En 1840 la Sociedad Económica de Amigos del País organizó una exposición sobre el avance industrial de la ciudad en los salones del Liceo. Entre otras muestras y objetos pertenecientes a las industrias malagueñas Mitjana concurrió con un diseño del teatro Marcelo de Roma reconstruido, que por la corrección de su dibujo llamó la atención de quienes lo contemplaron ${ }^{38}$.

\subsection{El proyecto de arco de triunfo al Duque de la Victoria}

Esta misma línea clasicista se pone de manifiesto en un proyecto que no llegó a ejecutarse que en diciembre de 1840 presentó a la Diputación, cuya dedicatoria nos corrobora que, entre otros cargos oficiales, desempeñó también el de arquitecto provincial: "presentado a SE la Diputación Provincial por su arquitecto $\mathrm{D}^{\mathrm{n}}$. Rafael Mitjana...". El monumento era un arco de triunfo

35. Recientes investigaciones han comprobado que el sol ilumina el fondo de la cámara sepulcral el día del solsticio de otoño.

36. Ibid., 18

37. GARCÍA GÓMEZ, F.: La vivienda malagueña del siglo XIX I, Málaga 2000, 285.

38. MADOZ, P.: Diccionario Geográfico-Estadístico-Histórico de España y sus posesiones de ultramar, Madrid, 1850, (edición facsímil de Ámbito Editorial, Salamanca 1986), 161. 
dedicado al general Baldomero Espartero, héroe de la independencia que en este momento acababa de obtener dos grandes éxitos políticos en el convenio de Vergara (1839), que puso fin a la guerra carlista del Norte, y la conquista de la ciudad castellonense de Morella, con la que le puso conclusión definitiva (1840).

El monumento se mantenía en la línea de exaltación cívica que era habitual en esta época. De tres vanos, el central era de medio punto con rosca moldurada y clave resaltada y los laterales, de menores proporciones, adintelados, y el orden sustentante el corintio. Sobre los dinteles sendas cartelas circundadas con panoplias militares mostraban los nombres de "Morella 1840" y "Ramales 1839", y sobre ellas grandes relieves que escenificaban las batallas que permitieron obtener estos dos grandes éxitos militares. En las enjutas del arco central dos grandes ángeles en airosa actitud de vuelo sustentaban laureas alusivas a la victoria.

Sobre el entablamento, en un segundo cuerpo, tres grandes recuadros moldurados acogían a los textos con las dedicatorias. El central destinado a Espartero, resaltando su condición de duque de la Victoria y de capitán general de los ejércitos nacionales, y los laterales a la milicia nacional y al ejército español, respectivamente, exaltando valores como el civismo, la constancia, el valor y la lealtad en la defensa de los derechos del pueblo, dotando al monumento del carácter ejemplarizante que ostentaba el monumento público en el periodo decimonónico. Remataban la obra panoplias militares en los extremos y un gran escudo nacional en el centro.

El proyecto fue entregado a la Diputación acompañado de memoria, presupuesto y del arbitrio previsto para su ejecución, aunque al final -probablemente por razones de costo económico-, no llegó a ser ejecutado, pero el diseño nos viene a demostrar las excelentes cualidades para el dibujo que tenía Mitjana.

\subsection{El monumento a Torrijos}

El monumento-mausoleo erigido a la memoria del general José $\mathrm{M}^{\mathrm{a}}$. Torrijos y los 48 compañeros mandados fusilar por Fernando VII goza de una gran presencia en la ciudad, tanto física como ideológica, y es -no solo la obra cumbre de su autor-, sino la obra arquitectónica por la que casi exclusivamente se le ha conocido hasta ahora.

Aunque el fusilamiento tuvo lugar en 1831 hubo que esperar al cambio de signo del régimen monárquico para que el Ayuntamiento pudiese promover este monumento, que fue sufragado por suscripción popular y en cuya ejecución se empleó arena del lugar del ajusticiamiento con la intención de incrementar el carácter simbólico de este homenaje rendido por el pueblo de Málaga. 


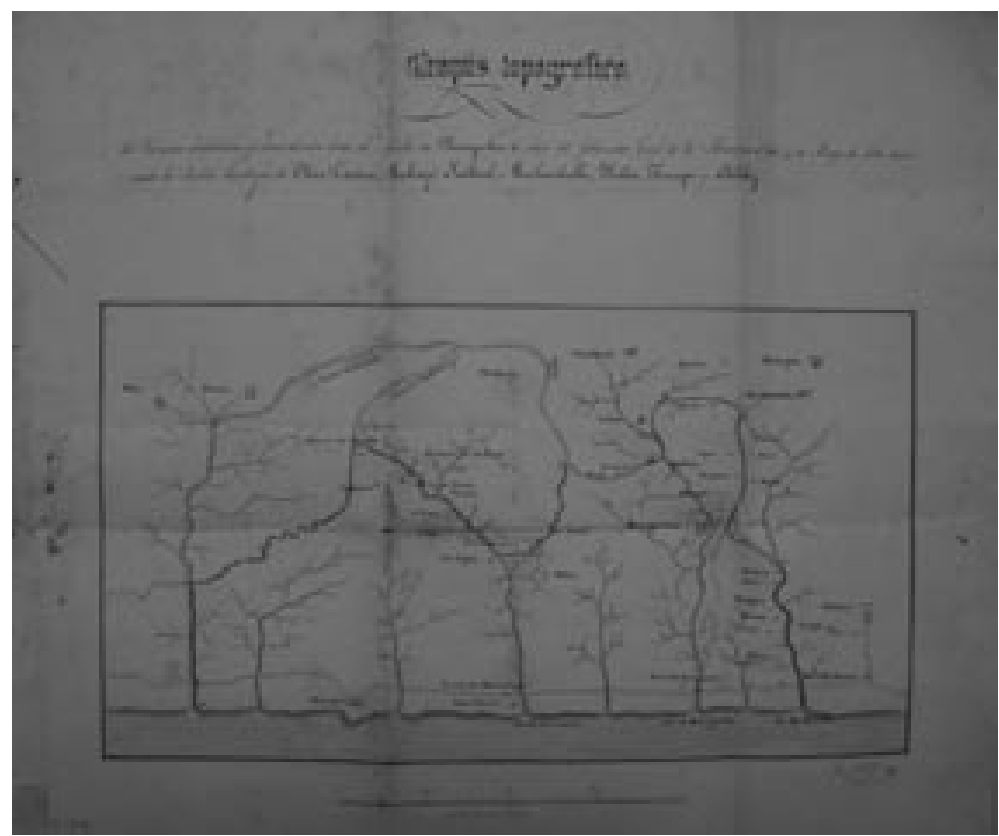

14. Representación cartográfica de la delimitación de pueblos de la Axarquía malagueña (A.M.M.)

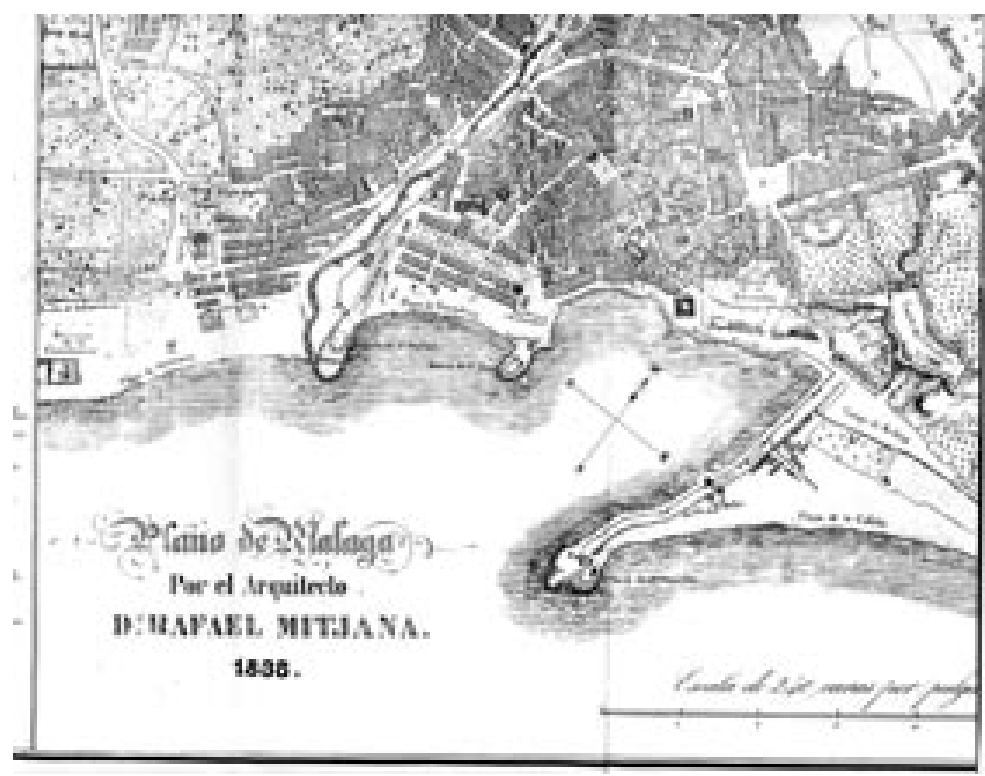

15. Detalle del plano de Málaga, 1838 


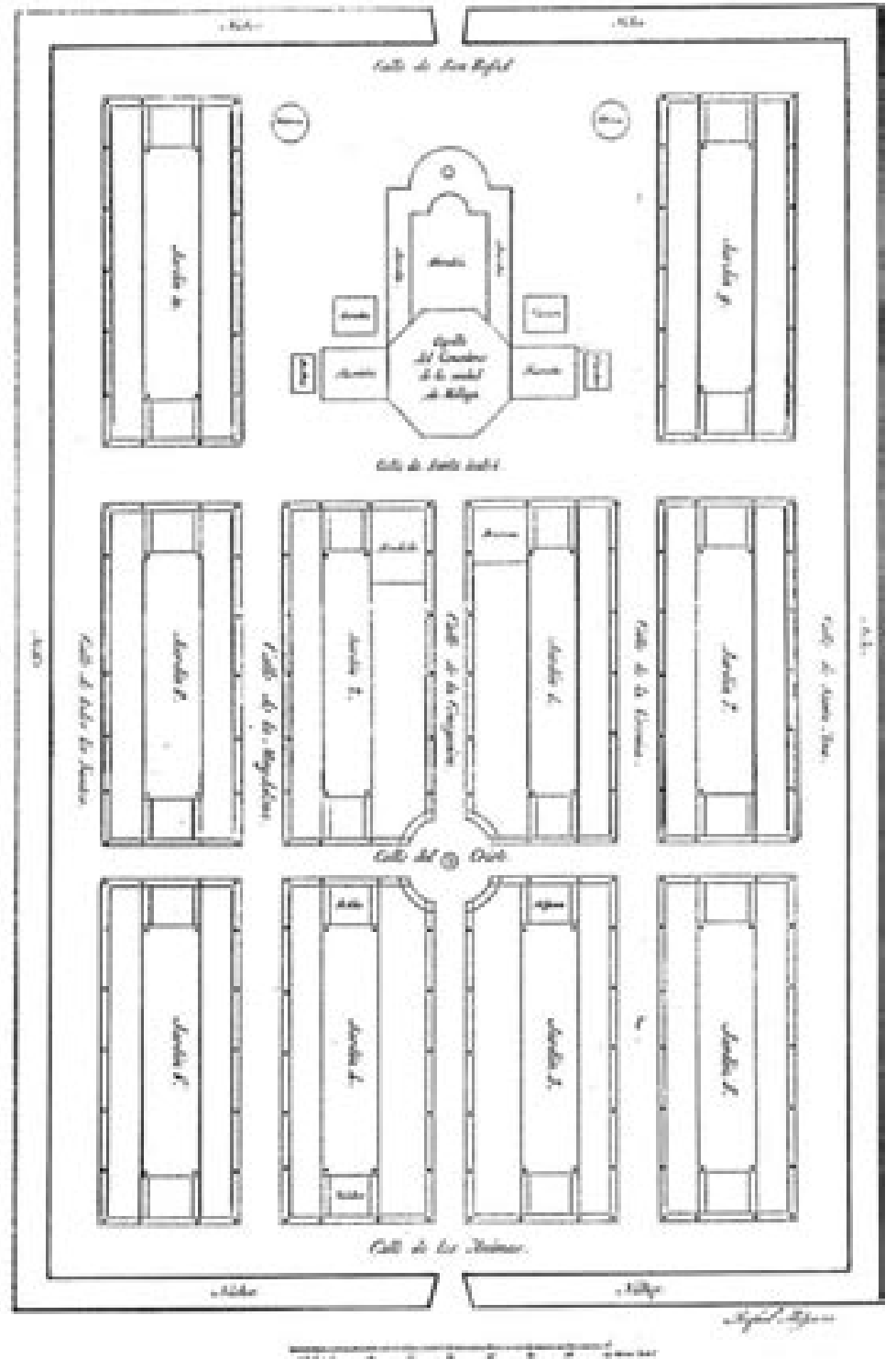

16. Plano del cementerio de San Miguel litografiado (A.M.M.) 
Al concurso público convocado concurrieron Cirilo Salinas y José Trigueros, con dos proyectos cada uno, Manuel de Mesa ${ }^{39}$-con un proyecto excesivamente retórico-, y Rafael Mitjana, que fue el seleccionado. Mitjana era en ese momento arquitecto municipal, y por tanto el dictamen faltó a la ecuanimidad, pero lo cierto es que su proyecto, más sencillo y económico y a su vez con una enorme carga simbólica, era el que más se ajustaba al modelo de monumento cívico imperante en la época. No obstante, en 1841, un año antes del inicio de la obra, el Ayuntamiento mandó colocar en el edificio consistorial una lápida conmemorativa, al parecer con escasa fortuna. Mitjana se ofreció para mejorar la actuación asumiendo el costo de un marco dorado e incluso donando un enseña militar salvada por él en una operación militar durante el trienio liberal, gesto con el que volvió a ganarse la adhesión y preferencias de la corporación ${ }^{40}$.

Omitiendo los avatares acaecidos durante todo el proceso de gestación de la obra ${ }^{41}$-incluyendo un viaje de Mitjana a Antequera para valorar el posible reaprovechamiento de otros restos monumentales-, la primera piedra fue puesta el 17 de abril de 1842 y el monumento se consideró concluido el 10 de diciembre de 1842, el día anterior al previsto para su inauguración. Fue necesario un segundo proyecto de Mitjana simplificando el primero para así poder agilizar el ritmo de las obras y abaratar su coste, a cuyo pesar el Ayuntamiento quedó como deudor del experimentado cantero Agustín Medina, que fue quien en la práctica corrió con su ejecución material.

Del proyecto original subsistieron la composición pétrea en sucesión vertical de basamento, pieza diédrica y obelisco, así como las cartelas circundadas de decoración barroquizante con textos edificantes y los nombres de los mártires en letras doradas ${ }^{42}$, así como las grandes volutas angulares y las laureas en sucesión vertical. Se eliminaron los trofeos miliares y se sustituyó la escultura alegórica de la fama por una laurea coronando el conjunto.

Para la composición pétrea se utilizó piedra jaspón procedente de las canteras de San Telmo, mientras que los elementos férreos -de una sorprendente calidad que ha facilitado su conservación-, fueron elaborados en la ferrería de Heredia. Para incrementar su estabilidad el monumento dispone de una espiga o vástago metálico interior, y entre las diferentes piezas que se superponían unas piqueras o aberturas sirvieron para verter plomo fundido que tomó cuerpo por el elemento metálico central. En consonancia con las técnicas construc-

39. SÁNCHEZ LÓPEZ, J.A.: La voz de las estatuas. Escultura, arte público y paisajes urbanos de Málaga, Málaga 2005, 126.

40. Ibid., 120

41. Remito a MORALES FOLGUERA, J.M.: Málaga... op. cit., 57-68.

42. Perdido el dorado con el paso del tiempo, así lo describe MADOZ, P.: op. cit., 142-3. El mismo autor estimó el costo final de la obra en 8.000 duros. 
tivas de la época, se dispusieron planchas de plomo para mejorar el asiento entre los bloques de piedra una vez desalojada la arena empleada para facilitar el movimiento de las piezas buscando su posición ${ }^{43}$.

\section{RAFAEL MITJANA Y EL URBANISMO}

\subsection{Actuaciones sobre el solar del convento de San Luis el Real}

Tras la obtención del título de arquitecto en 1835 Mitjana era uno de los pocos facultados para actuar en una ciudad que aún no había experimentado el extraordinario auge derivado de su desarrollo industrial, aún en su fase inicial. Uno de los procesos que contribuyó a transformar la ciudad fue la desamortización, cuya primera etapa fue consecuencia de la legislación propiciada por el ministro Mendizábal. Aunque la finalidad de esta medida era favorecer el bien común, la burguesía industrial y los personajes influyentes fueron los más directamente beneficiados por los terrenos liberados de uso religioso y que salían a pública subasta.

Este fue el caso de del convento franciscano de San Luis el Real, fundado tras la reconquista extramuros y cuya considerable extensión había quedado en una inmejorable y céntrica situación circundada por el barrio de San Rafael ${ }^{44}$. En enero de 1836 ya se estaban desalojando a las hermandades que tenían sede canónica en su iglesia y se había decidido un uso docente para sus instalaciones. Pero en el verano de 1837 nada se había realizado y el arquitecto Rafael Mitjana, a requerimiento de Antonio $\mathrm{M}^{\mathrm{a}}$. Álvarez, gobernador civil y militar de la ciudad, emitió un informe relatando pormenorizadamente su mal estado de conservación. En el escrito se hacía alusión a las consecuencias del expolio al que había sido sometido el inmueble, al que faltaban los herrajes, puertas y otros elementos de valor, y el cegamiento de las atargeas hacía imposible el riego de su huerta. A los forjados de madera se les achacaba la pudrición de las vigas y a los muros de cerramiento, realizados en tapial y faltos de mantenimiento, el inicio de su desmoronamiento. El informe de Mitjana se hallaba claramente encaminado a orientar a la baja el valor real del solar y el inmueble, que estimó en 5.000 pesos fuertes, pues el aprovechamiento de los materiales no compensaría a los gastos de la demolición.

43. Agradezco estas y otras observaciones a $D^{a}$. Estrella Arcos von Haartman -directora de Quibla Restaura-, y D. Eduardo Gallego, resultado de la restauración realizada en el monumento en el año 2006.

44. RODRÍGUEZ MARÍN, F.J.: Málaga conventual. Estudio histórico, artístico y urbanístico de los conventos malagueños, Málaga 2000, 65-93 
Apoyado en el informe de Mitjana. Álvarez conminó al Ayuntamiento a que acelerase la subasta, que fue publicada en el Boletín Oficial del 1 de agosto de 1837 con un precio de salida de 70.000 reales, y que ante la ausencia de otro postor, fue adjudicada al propio Álvarez. Si comparamos esta cantidad con el precio con el que el mismo Mitjana había tasado una sola vivienda de la calle Almacenes en 1839 (41.978 rs.), advertiremos claramente la desproporción y el alcance económico de esta operación, que resultó extremadamente lucrativa para Álvarez. Con posterioridad el Ayuntamiento denunció varios vicios de forma que a su entender justificarían la nulidad de la adjudicación, pero el expediente se prolongó hasta 1867 sin que nada pudiese aclararse ${ }^{45}$.

Con esta y otras actuaciones Mitjana demostró no separar su condición de arquitecto de su sagacidad para los negocios, pues sobre el amplio solar obtenido Álvarez promovió la construcción de una plaza de toros, inversión que había de verse avalada por el éxito teniendo en cuenta la gran afición que generaba el espectáculo y que la ciudad carecía de un coso estable para acoger esta actividad. El coso, siguiendo la habitual forma circular, se ubicaba en el centro de la parcela, y aunque hubo otras intervenciones facultativas, la dirección de la obra correspondió a Mitjana. Se inauguró el 14 de agosto de 1840 realizado básicamente en madera, aunque posteriormente se fue sustituyendo este material por obra de cantería, disminuyendo la excesiva amplitud de su arena mediante la construcción de una terraza. El inmueble, como corresponde al estilo y formación de su autor, fue planteado siguiendo un lenguaje clasicista, y disponía de palcos, gradas, tribunas y varias puertas que garantizaban una rápida evacuación ${ }^{46}$. Tras estas reformas la plaza ofrecía un aforo de 10.000 personas llegando a ser considerada de las mejores de España, tanto por sus dimensiones como por su solidez, aunque sus escasas corridas no siempre satisfacían las expectativas del público ${ }^{47}$. Quizás por esta razón en 1864 fue derribada ${ }^{48}$ para abrir paso a nuevos aprovechamientos del solar.

Casi simultáneamente a la construcción de la plaza de toros proyectó un conjunto de tres viviendas en la plaza de San Francisco esquina a la calleja de

45. A.M.M. legajo 17-C

46. CARRERA, J.: "Historial de las plazas de toros malagueñas", Diario SUR, Málaga, 18/ XI/1941 y DÍAZ ESCOVAR, N.: "Antiguallas curiosas de Málaga y su provincia. La inauguración de la plaza de Álvarez”, Málaga, s/f. Archivo Temboury.

47. VILA, B.: Guía del viajero en Málaga, Málaga 1861, 17. Sólo se le autorizaban diez corridas al año. Del cartel de la inauguración -que representa un grabado con la única vista que se conoce-, reproducido en BEJARANO, R.: "Málaga y sus plazas de toros", Jábega 5, 1974, 39.

48. MORALES FOLGUERA, J.M.: "La arquitectura y el urbanismo: del Antiguo Régimen a la arquitectura del ocio", en VV.AA. (CAMACHO MARTÍNEZ, R. dtra.): Málaga, vol. III, Málaga 1984, 904 
Eduardo Ocón, de dos plantas de altura y rematadas con jarrones de cerámica, hoy desaparecidas ${ }^{49}$.

\subsection{Mitjana y la cartografía}

Una de las capacidades de Mitjana como arquitecto fue su facultad para asimilar el espacio y plasmarlo sobre el papel, lo que demostró con la elaboración de una cartografía general de la ciudad en 1838. Con estas características el plano inmediatamente anterior era el realizado por Onofre Rodríguez en 1805 , y lo cierto es que la ciudad había crecido en el transcurso de tiempo que medió entre uno y otro. Según sus propias declaraciones, para elaborarlo mandó traer desde Londres un teodolito, realizado por el mecánico Tronghton, quien tenía reconocimiento en esta labor, así como una plancheta. Mitjana invirtió en su elaboración siete meses y aprovechó su elaboración para insertarlo en una Guía.

Nada más terminarlo regaló al Ayuntamiento un ejemplar enmarcado y seis copias realizadas en su taller litográfico, rogando que una de ellas quedase incorporada a las actas capitulares de aquel año, pues sin duda juzgaba que este era el medio más seguro para que se conservase en el futuro al menos un ejemplar de su obra.

En el escrito que acompañaba a la entrega, fechado en 11 de febrero de 1838, afirmaba que lo había realizado a sus expensas, pues consideraba que hacía falta un plano grande de la ciudad y su término, privilegio que estimaba reservado para el arquitecto elegido por el Ayuntamiento, especificando que se trataba de un obsequio por considerarse hijo de la ciudad ${ }^{50}$. Juzgándolos de gran utilidad para el ejercicio de las funciones municipales, se acordó adquirir nuevos ejemplares para que pudiese entregarse un ejemplar a cada regidor ${ }^{51}$.

Unos días más tarde -quizás tras comprobar la excelente acogida que su regalo había obtenido entre las autoridades-, el 20 de febrero de 1838 regaló a la Diputación 24 planos, uno de ellos enmarcado, que la corporación supramunicipal, con todo honor, acordó igualmente instalar en su salón de sesiones.

Sin embargo este plano fue también motivo de disgustos, pues en una tertulia en la que estuvo presente su amigo, el Sr. Osman, se había afirmado que el plano copiaba a otro realizado anteriormente por el arquitecto Cirilo Salinas. Esta acusación dio lugar a una airada como argumentada refutación por parte de Mitjana, que para general conocimiento fue publicada en el Boletín

49. A.M.M. legajo 1362 exp. 102.

50. A.M.M., legajo 1382 (II), expediente 78.

51. A.M.M., Actas Capitulares vol. 237, f $\mathrm{f}^{\mathrm{D}}$. 55v., sesión 20 de febrero de 1838. Sin embargo, en el tomo correspondiente de actas no figura el mencionado ejemplar. 

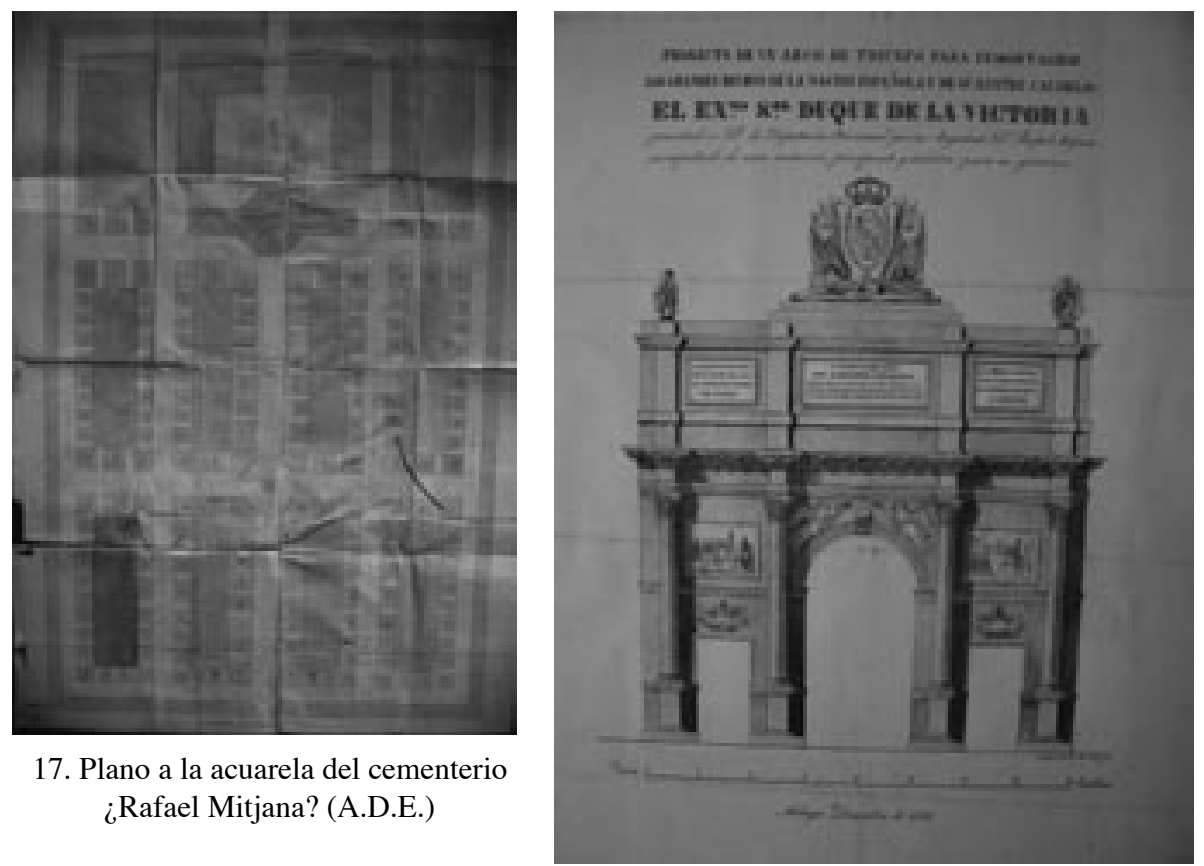

17. Plano a la acuarela del cementerio ¿Rafael Mitjana? (A.D.E.)

18. Proyecto de arco de triunfo dedicado al duque de la Victoria (A.D.E.)

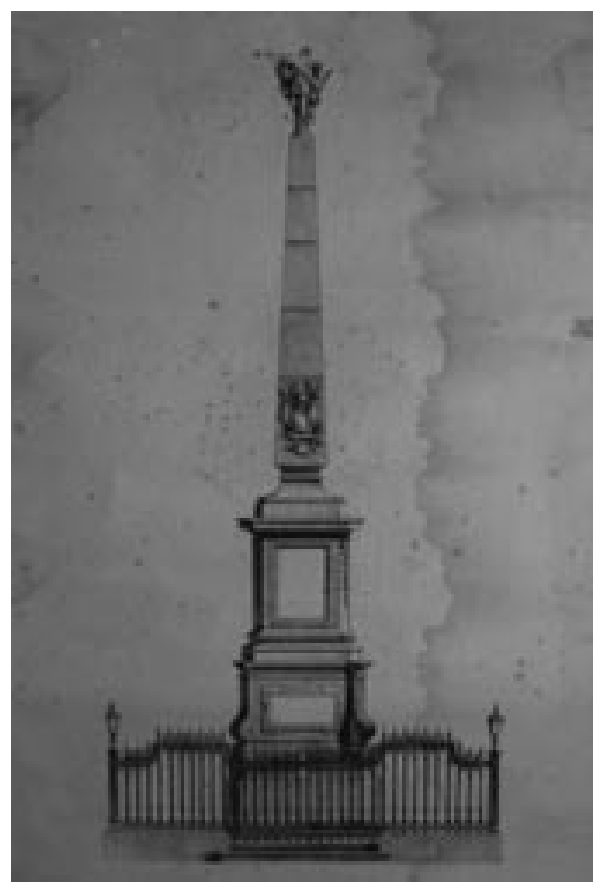

19. Primer proyecto de monumento a Torrijos (A.M.M.) 


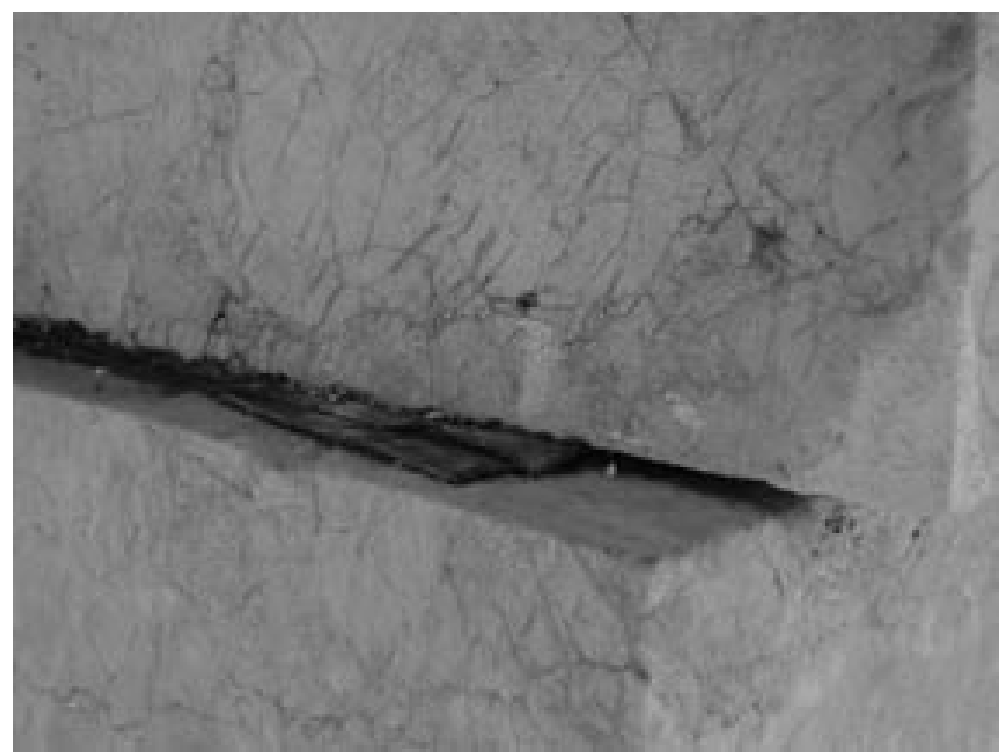

20. Detalle del asiento de la piedra con planchas de plomo en el monumento a Torrijos

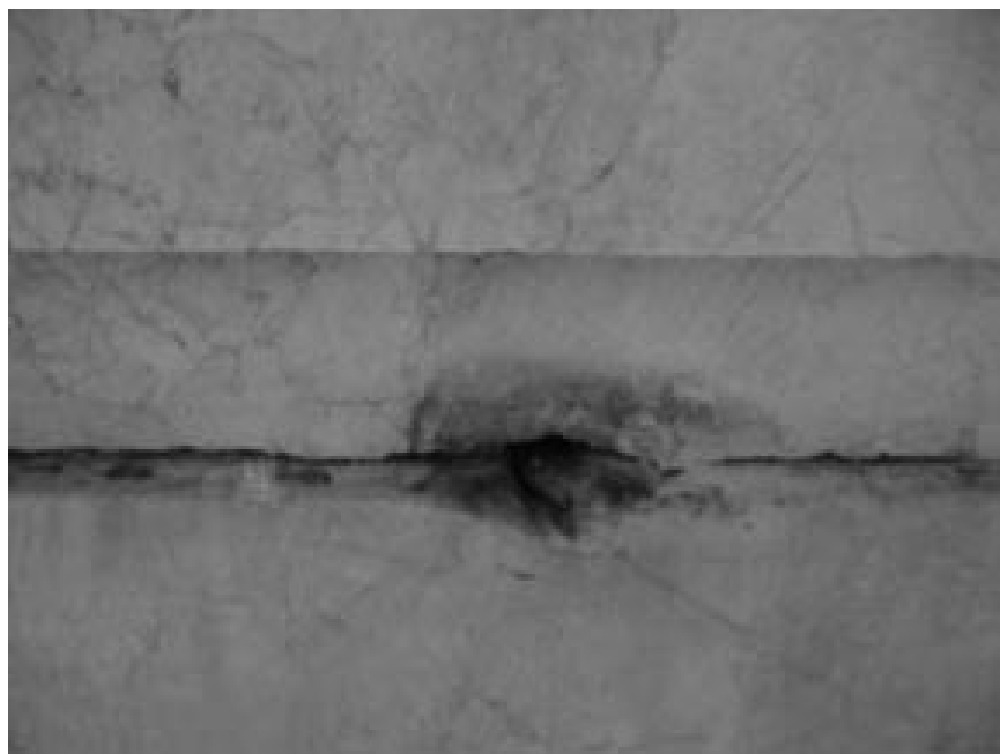

21. Detalle de la piquera para verter plomo fundido en el monumento a Torrijos 
Oficial de la Provincia de Málaga ${ }^{52}$. En su prolija argumentación explicaba que -aunque él no lo tuvo en cuenta-, el plano realizado por Salinas era copia de otro del año 1800 que le había regalado el maestro carpintero José Sánchez, y que por tanto no se correspondía con la realidad de la ciudad de entonces. Apoyó su afirmación aportando el dato de la reciente publicación (en 1837) de un plano de España en 12 grandes pliegos por parte del geógrafo Mr. Dufour, y que no pudo valerse de ninguno de la ciudad de Málaga, pues el publicado en 1806 por Juan Manuel de Arejula en su trabajo sobre la fiebre amarilla, era igualmente inexacto. No obstante, Mitjana quiso dejar claro que quizás los difusores de la infamia habían interpretado mal algunas palabras de Cirilo Salinas, exculpando con ello a su colega de mala intención.

Lo cierto es que el plano -cuya íntegra autoría Mitjana asumió con total rotundidad-, está elaborado con gran precisión, claridad y conteniendo gran cantidad de nombres de hitos y lugares, abarcando también a los barrios perimetrales y las huertas que circundaban a la ciudad, identificándolas con sus nombres, así como los caminos y arroyos. En márgenes laterales enumeró a las plazas, placetas, iglesias y edificios públicos. Probablemente por todo ello este ha sido el plano histórico de la ciudad más conocido y difundido. Una reproducción del mismo se incluyó en la obra de Vicente Martínez Montes Topografía Médica de la ciudad de Málaga, publicada en 1852.

Aunque su prematuro fallecimiento lo impidió, sabemos que estuvo bastantes años recorriendo la provincia de Málaga, anotando accidentes geográficos y estadísticas climatológicas que destinaba a la elaboración de un plano provincial que no llegó a realizar. Como anticipo a este proyecto podemos mencionar algunas representaciones cartográficas parciales, como la realizada para los deslindes de los términos municipales de Benagalbón, Olías, Totalán, Moclinejo, Sandoval, Macharaviaya, Valdés, Benaque y Chilches, dibujada en 1836, apenas recién iniciada su actividad como arquitecto ${ }^{53}$.

\subsection{Ampliación y reordenación del cementerio de San Miguel}

También pasa por considerarse una de las actuaciones urbanísticas más destacadas de Mitjana el proceso de ampliación y reordenación del cementerio de San Miguel. El camposanto había sido inaugurado el 1 de julio de 1810 con enormes deficiencias en cuanto a dotaciones, pues el muro de cerramiento, al

52. Boletín Oficial Literario, Industrial y Mercantil $\mathrm{n}^{\circ} .1372,11$ de marzo de 1838 . Citado por LLORDÉN, P.A. (O.S.A.).: Arquitectos y canteros malagueños, Ávila 1962, 231

53. A.M.M., legajo 21-C expediente 7. Recogido en BARRIONUEVO, R. y MAIRAL, C.: op. cit. 
que se fueron adosando los nichos de las cofradías, no se inició hasta 1827, concluyéndose dos años más tarde ${ }^{54}$.

En el interior del enorme rectángulo se erigieron la capilla de Santa Isabel de Hungría y el triunfo de la Inmaculada procedente del convento de San Pedro Alcántara una vez que éste fue desamortizado. Por lo demás, hubo de acoger inhumaciones en el suelo de una forma un tanto anárquica, de modo que pronto fue imposible excavar sin topar con restos humanos, a lo que sumó -quizás esto último con mayor determinación-, la demanda de parcelas por parte de la burguesía y familias acomodadas para construir mausoleos monumentales.

En noviembre de 1847 José Marín García remitió al cabildo municipal un escrito argumentando que el único patio del camposanto se hallaba saturado y que ante la imposibilidad de seguir excavando en su suelo era necesario acometer una ampliación. Aludía en su escrito a la intención de restaurar la capilla dotándola de sacristía, depósito de cadáveres y dependencias para las hermandades, así como a la intención de plantar árboles y plantas aromáticas, operaciones que en su conjunto dignificarían al cementerio.

La propuesta se concretaba en la adquisición de un terreno lindero con el camposanto por su lado Norte, ocupando la misma anchura de éste y con el que se comunicaría por una portada. La habilitación de este nuevo espacio y la reordenación del camposanto existente permitía vender las parcelas al precio de 100 rs. la vara en las calles de la Concepción, del Cristo y de Santa Isabel, y a 80 rs. en las calles de Todos los Santos, Magdalena, Verónica, Santa Ana y las Ánimas, cuya posición era menos privilegiada teniendo en cuanta al eje axial o principal y la posición de la puerta de entrada y la capilla, incorporando un criterio de jerarquización del espacio.

En su calidad de arquitecto municipal, Mitjana fue el encargado de proyectar y presupuestar la obra, determinando que era necesario adquirir una porción de 164 varas de largo y 60 de ancho (9.840 varas cuadradas equivalentes a 13 1/2 celemines), de un terreno poco cotizado por su mala calidad y cuya compra presupuestó en 3.000 rs. En comparación, resultó más caro la construcción del muro de cerramiento, en total 1.200 metros lineales de una tapia de 4 varas de altura (incluyendo los cimientos) y 18 pulgadas de espesor, construida en mampostería, ladrillo y argamasa de cal y arena, enfoscada y enlucida a la cal, cuyo costo ascendía a 17.000 rs. La realización de la portada de comunicación entre ambos sectores costaba 1.900 rs y otros conceptos, como la albardilla de coronamiento del muro elevaba el total a $24.000 \mathrm{rs}$.

54. RODRÍGUEZ MARÍN, F.J.: "Resumen histórico de los cementerios de Málaga en la época contemporánea", en Una Arquitectura para la muerte, I Congreso Internacional de Cementerios contemporáneos, Sevilla, 4-7 junio 1991, Sevilla 1993, 538. 
Los cálculos de la corporación municipal eran que los derechos de inhumación y los ingresos obtenidos por la venta de parcelas para construir mausoleos en el sector antiguo, sufragasen el costo de la obra en su totalidad. El 4 de diciembre de 1847 aprobó el Ayuntamiento la compra de los terrenos y el 12 de febrero Mitjana remitió 40 planos del cementerio elaborados a sus expensas (recordemos que era propietario de un taller litográfico), con el específico fin de que se destinasen a la publicidad de la obra y se distribuyesen entre los concejales y los adquirientes de los terrenos. El 17 de febrero de 1848 se abrió el plazo de recogida de solicitudes para adquirir terrenos ${ }^{55}$. De esta forma, una de las actuaciones que más contribuyó a dignificar el cementerio -el actual patio $1^{\circ}-$, responsable de la imagen ordenada que aún conserva, se nos muestra simultáneamente como una operación comercial que aportó al municipio saneados ingresos. La ampliación, actualmente conservada como patio $3^{\circ}$., se comunica con la zona más antigua mediante la gran portada en forma de arco de medio punto que se mantendrá tras el proceso de reformas que actualmente se acomete en el cementerio más antiguo y monumental de la ciudad.

\section{LA ACCIÓN FACULTATIVA EN LA EXTINCIÓN DE INCENDIOS EN MÁLAGA}

Agravado por las técnicas constructivas al uso, el empleo de materiales fungibles y el urbanismo característico del Antiguo Régimen, en el que la estrechez de las calles contribuían por igual a la propagación como a dificultar la llegada de auxilio, los incendios fueron uno de los graves problemas de las ciudades. Efectos tan devastadores como el que tuvo lugar en Londres en 1666 pone de relieve las consecuencias de la carencia de un cuerpo específicamente adiestrado y técnicamente dotado en sofocar los incendios.

El punto de partida en España se halló en la creación en 1834 de la Milicia Nacional, en cuyo seno se creó una brigada de Zapadores Bomberos con el cometido de actuar en caso de incendio, que en Málaga funcionó desde 1835. Este fue el año en el que Rafael Mitjana obtuvo el título de arquitecto y de forma casi inmediata pasó a dirigir esta brigada con el cargo de capitán de Milicias $^{56}$.

Su paso por esta actividad fue controvertido, pues a sus conocimientos y dedicación se le unían sus continuas demandas de material y personal, así

55. A.D.E., caja 353, documento 19.

56. DE MATEO AVILÉS, E. y GARCÍA DE CASTRO, A.J.: Pasado y presente del Real Cuerpo de Bomberos de Málaga, Málaga 2004, 23. 
como que éste estuviese debidamente compensado ${ }^{57}$. El servicio estaba integrado, de forma efectiva, por unos 80 voluntarios que tras cada actuación eran gratificados con un estipendio de entre 2 y 4 rs. y una entrega de pan y vino, cuando se daba el caso que las rudimentarias bombas impulsoras que se utilizaban requerían como mínimo de este número de operarios, dejando desasistidas a las demás necesidades. Mitjana intentó sortear esta situación reclamando subvenciones y material tan básico como una escalera extensible con la que poder salvar personas y enseres del segundo y tercer piso de las viviendas. Finalmente, ante la dejadez de la situación, presentó su dimisión, siendo sustituido por el arquitecto José Trigueros, quien lo estuvo hasta que la compañía se disolvió en 1844.

Pero esta renuncia de Mitjana -sin duda justificada-, escondía otra motivación. El 15 de diciembre de 1839 se había constituido la Sociedad de Seguros Mutuos de Incendios de Edificios, de carácter privado, cuyos cometidos esenciales era indemnizar a los afectados previa tasación de daños por parte de sus arquitectos, pero también acudir a sofocar los incendios con sus propios medios y personal. Su arquitecto fue nuevamente Rafael Mitjana, quien era ya por entonces arquitecto municipal, y al que la ley era una de las pocas autoridades al que autorizaba el acceso a un incendio declarado, ya fuese atendido por los zapadores de las Milicias (un cuerpo militarizado, público y más popular), o la Mutua, de carácter privado y preferida por la alta burguesía.

Esta situación ocasionó durante años equívocos acerca de si los zapadores bomberos debían acudir a una casa incendiada perteneciente a la Mutua ${ }^{58}$, asî como fricciones de competencias entre ambos cuerpos. Sin embargo volvió a reproducirse la falta de entendimiento entre Rafael Mitjana y la dirección de la Mutualidad, uno de cuyos episodios más destacables fue el rechazo a sus cuentas de gastos en 1847, lo que obligó al arquitecto a asumir el costo de una compra de material. También se quejaba Mitjana de la desproporción entre las retribuciones de personal argumentándolo con datos: en 1847 se retribuyó a los trabajadores y al arquitecto con 1.700 rs., mientras que en el mismo periodo el gasto de personal administrativo había ascendido a 5.040 rs. Mitjana afirmó defender los intereses de la clase obrera, pero a la vez también defendía los suyos.

57. Los primeros años de este servicio están marcados por las carencias de medios y el voluntarismo de sus miembros. El servicio tenía su sede en un portal en el Arco de Granada. Vid. A.M.M., Actas Capitulares vol 237, fo. 42v., sesión 5 de febrero de 1838. "El ayuntamiento acordó el pago de 1952 reales a que ascienden los presupuestos de haberes de los batallones art. Bomberos y la caballería en la $2^{\text {a }}$ quincena de este mes aprobados que sean por la comisión. Ibid. $\mathrm{F}^{\circ}$. 60v, sesión 20 de febrero de 1838.

58. Las viviendas protegidas por la Mutualidad se señalaban con una placa de cerámica vidriada con el texto "ASEGURADA DE INCENDIOS", que aún pueden observarse en numerosas casas del casco histórico. 


\section{4xas) \\ nim $=$ \\ TEMPLO DRUIDA}

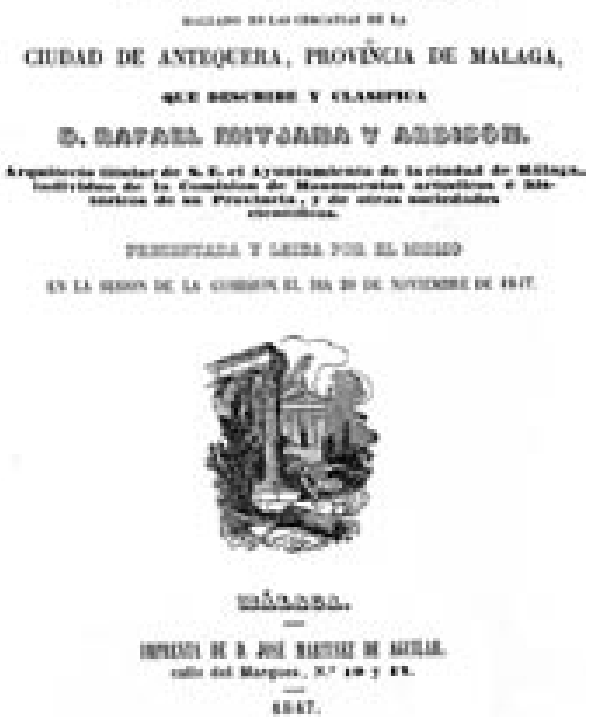

22. Portada del opúsculo sobre los dólmenes de Antequera (A.M.M.)

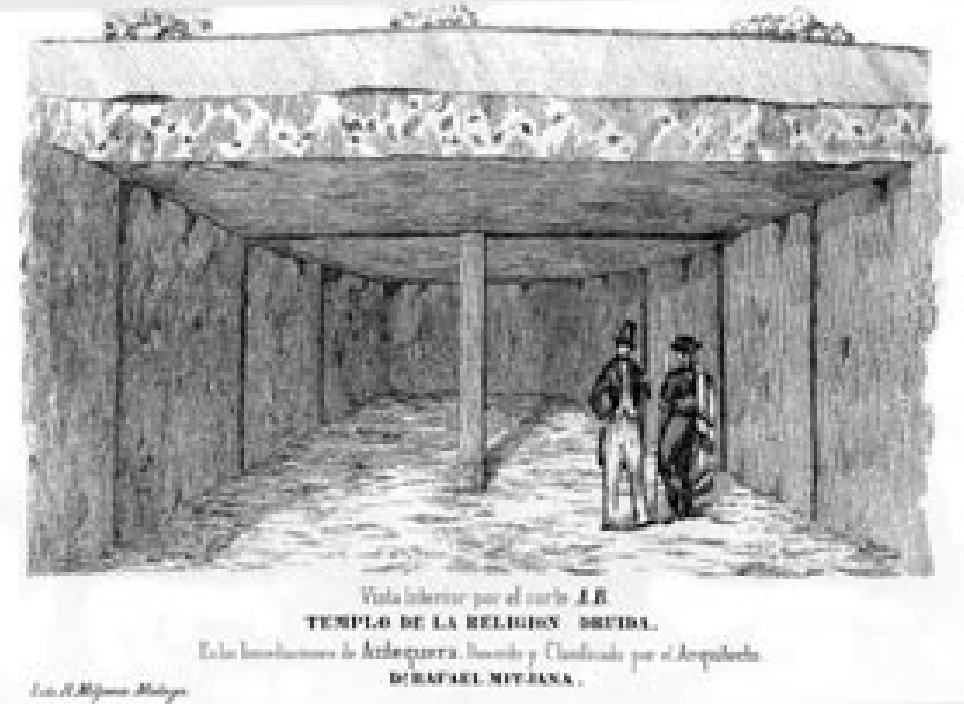

23. Representación litográfica del interior de la galería dolménica (A.M.M.) 


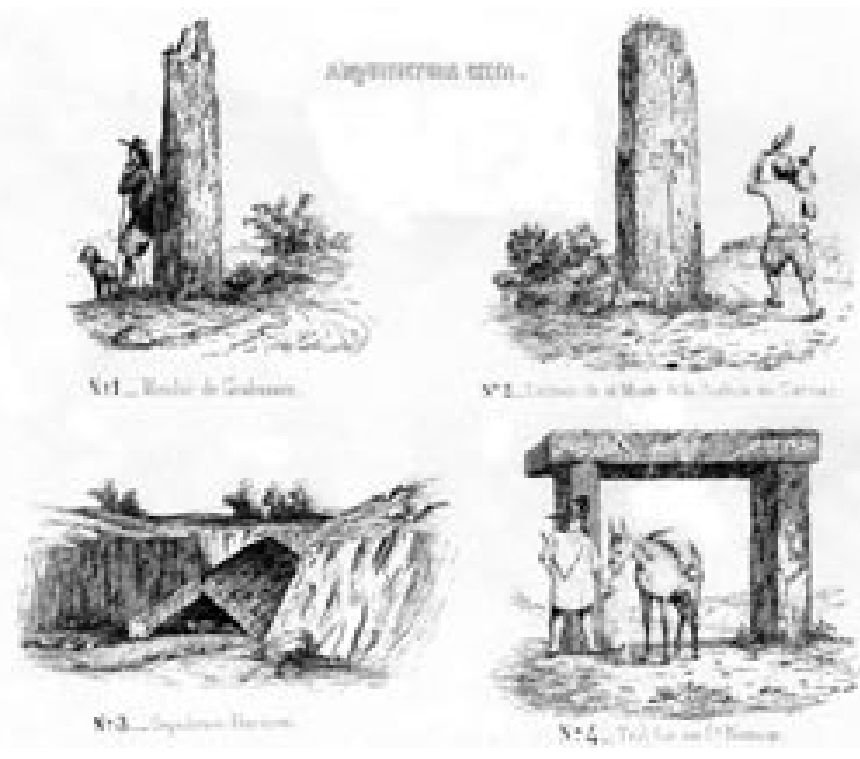

24. Representaciones litográficas de monumentos megalíticos con los que Mitjana comparó el de Antequera (A.M.M.)

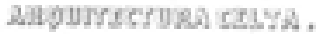
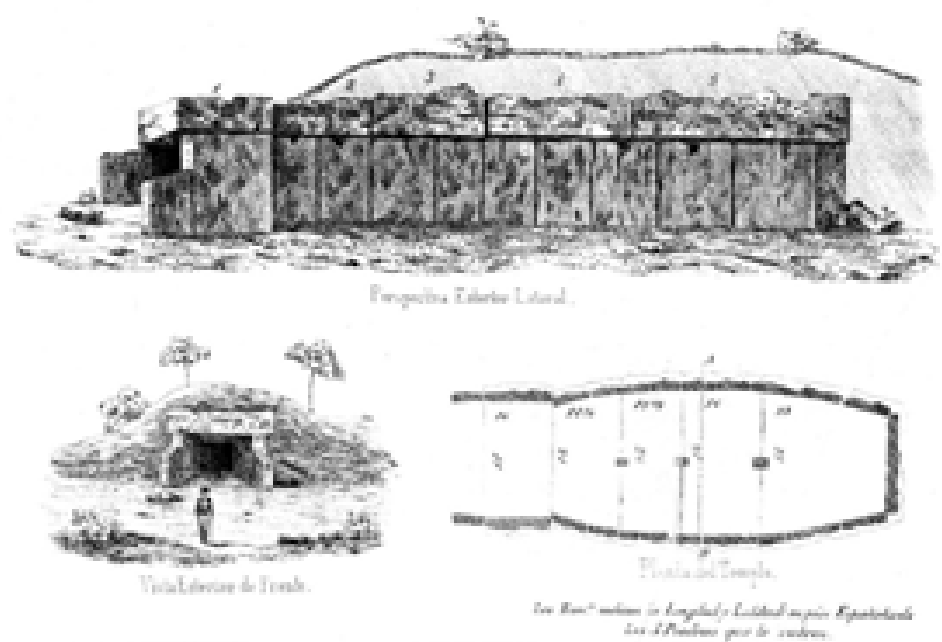

25. Sección del dolmen de Antequera. R. Mitjana (A.M.M.) 
El último episodio de este desencuentro sobrevino dentro del marco de las competencias, pues la sociedad había nombrado como arquitecto segundo a Manuel de Mesa, quien ausentado en Madrid dejaba a Mitjana al frente de todas las responsabilidades. En 1848 la dirección nombró para este puesto de arquitecto segundo a José Trigueros sin consultarle, lo que motivó la dimisión de Mitjana, pasando Trigueros a ser arquitecto primero y Cirilo Salinas segundo ${ }^{59}$.

Mitjana no se conformó con marcharse, sino que quiso que todos los asociados tuviesen conocimiento de sus razones, y por ello hizo imprimir un opúsculo $^{60}$ en el que reprodujo literalmente todos los oficios cruzados entre la Junta de la Mutualidad y él mismo, argumentando lo justificado de sus reclamaciones. Entre otras quejas se hallaba el que la Sociedad exigiese a los trabajadores que acudiesen a sofocar el incendio que portasen el preceptivo cinturón identificativo para que se les abonase el jornal, perjudicando, a juicio del arquitecto, la premura en atender el peligro, pues debían trasladarse antes a los almacenes de Santo Domingo para recoger este material. Otras quejas se fundamentaban en la reclamación de una paga de 600 rs. por Pascua de Navidad para los trabajadores, o el considerarse mal valorado y retribuido, pues Mitjana pensaba -probablemente con toda razón-, que era el alma de la Mutualidad, siempre presente en cada siniestro en los que arriesgaba su integridad física, a lo que había de sumar el trato y gobierno con los trabajadores -que sólo le conocían a él-, y la inspección de las nuevas casas acogidas a la Mutualidad $^{61}$, que en número de unas 300 cada año apenas le suponían 3 rs. que no compensaba ni los desplazamientos.

\section{CONCLUSIONES}

El interés por la figura de Rafael Mitjana sobrepasa su condición de arquitecto, a pesar de que ha sido uno de los personajes menos tratados por la historiografía local. Hijo de comerciante, con tradición militar y nacido en Má-

59. DE MATEO AVILÉS, E.: La Sociedad de Seguros contra incendios de edificios y los orígenes del Servicio de Bomberos en Málaga durante el siglo XIX, Málaga 2000, 18-49.

60. MITJANA, R.: A los sres. Socios de la Sociedad de Seguros Mutuos contra incendios de esta ciudad, Málaga, 1848.

61. Como ejemplo, sirva el presente documento, informe de una actuación dirigida por Mitjana: "Anoche, a las 7 1 1/2 las campanas tocaron a fuego, de la casa $n^{\circ} .67$ de la calle Nueva, en el $2^{\circ}$ piso. A las $9 \frac{1}{2}$ el fuego estaba en su mayor fuerza y fue bajando con el auxilio de agua. A las 10`30 estaba dominado, y a las 11 concluido. Durante toda la noche los trabajadores de la sociedad de Seguros mutuo no dejaron de refrescar con una bomba y 36 cubos. 29 de febrero de 1844. El arquitecto de la ... Rafael Mitjana”. Vid. A.M.M., legajo 2097 
laga, donde se inicia como inquieto y activo comerciante. Las transacciones y reinversiones de su capital demuestran su necesidad de prosperar en una ciudad que iniciaba un despegue económico del que no quiso quedar al margen. No es intrascendente que ya en posesión del título de arquitecto y con reconocimiento en esta actividad se empadronase en algunas ocasiones como comerciante.

No puede negarse su espíritu generoso a la hora de acometer trabajos, como el levantamiento cartográfico de la ciudad o el fallido de la provincia, que nadie antes había realizado y que regaló entre las instituciones, aprovechando la circunstancia de poseer un taller litográfico y de fabricación de abanicos. Pero no es menos cierto que estas u otras actuaciones le reportaron grandes beneficios, pues le ayudaron a prosperar y a obtener reconocimiento. Su entendimiento con algunos de los más destacados promotores facilitó la realización de lucrativas operaciones inmobiliarias sobre la que planea la sombra de la ausencia de claridad.

Pero a su vez el suyo era también un carácter inconformista e insumiso que le llevó a enfrentarse con empresas y particulares cuando sus derechos o el de sus trabajadores no eran respetados. Disfrutó de admiración por parte de la sociedad malagueña. El hecho de haber prestado sus servicios para un cúmulo diverso de instituciones u empresas particulares nos conducen hacia un profesional solvente y que supo venderse bien. Realizó pocas obras arquitectónicas privadas, pero a cambio prestó otros servicios y desarrolló una intensa actividad oficial.

La fecha en la que obtuvo su título de arquitecto, 1835 resulta determinante para el carácter academicista y clásico que trasluce su producción arquitectónica. El lenguaje y la impronta clásicos se encuentran presentes en sus diseños de monumentos, en el trazado del cementerio de San Miguel o en la severidad de su arquitectura doméstica. Estilística e ideológicamente concordaba plenamente con el espíritu de la Academia de San Fernando que lo habilitó y a la que nunca negó reconocimiento. Hasta 1844, que es cuando se creó la Escuela de Arquitectura de Madrid $^{62}$ renovando el panorama artístico y la formación de los arquitectos, el ejercicio de la profesión en España adolecía de una cierta uniformidad. Dentro de la nómina de arquitectos académicos y clasicistas, Mitjana perteneció a la denominada generación de $1800^{63}$, la que no había llegado a convivir con Villanueva y los grandes arquitectos neoclásicos, y que ejercieron de transición hasta que hacia la mediación del siglo XIX soplaron aires renovadores.

62. GARCÍA MELERO, J.E.: Arte español de la Ilustración y del siglo XIX. En torno a la imagen del pasado, Madrid 1998, 140.

63. NAVASCUES, P. y QUESADA MARTÍN, M ${ }^{\mathrm{a} . J} .:$ El siglo XIX. Bajo el signo del Romanticismo, Madrid 1992, 23. 
Su implicación en la erección de algunos monumentos públicos y sus actitudes, nos confirman las convicciones liberales de Mitjana, que llegó a compartir hechos de armas con algunos destacados militares de esta condición.

Fue persona de sólida formación cultural interesado en aspectos patrimoniales y al que no le importó invertir esfuerzos y su dinero en difundir sus avances, aunque a la larga ello fuese también en beneficio de su carrera profesional, prematuramente truncada. Sus proyectos conocidos -no siempre ejecutados-, sus habilidades para la práctica cartográfíca y la opinión de sus contemporáneos, nos confirman que nos hallamos ante una persona en la que se aunaban sus extraordinarias habilidades para el dibujo y la expresión artística, y a su vez una sólida formación técnica.

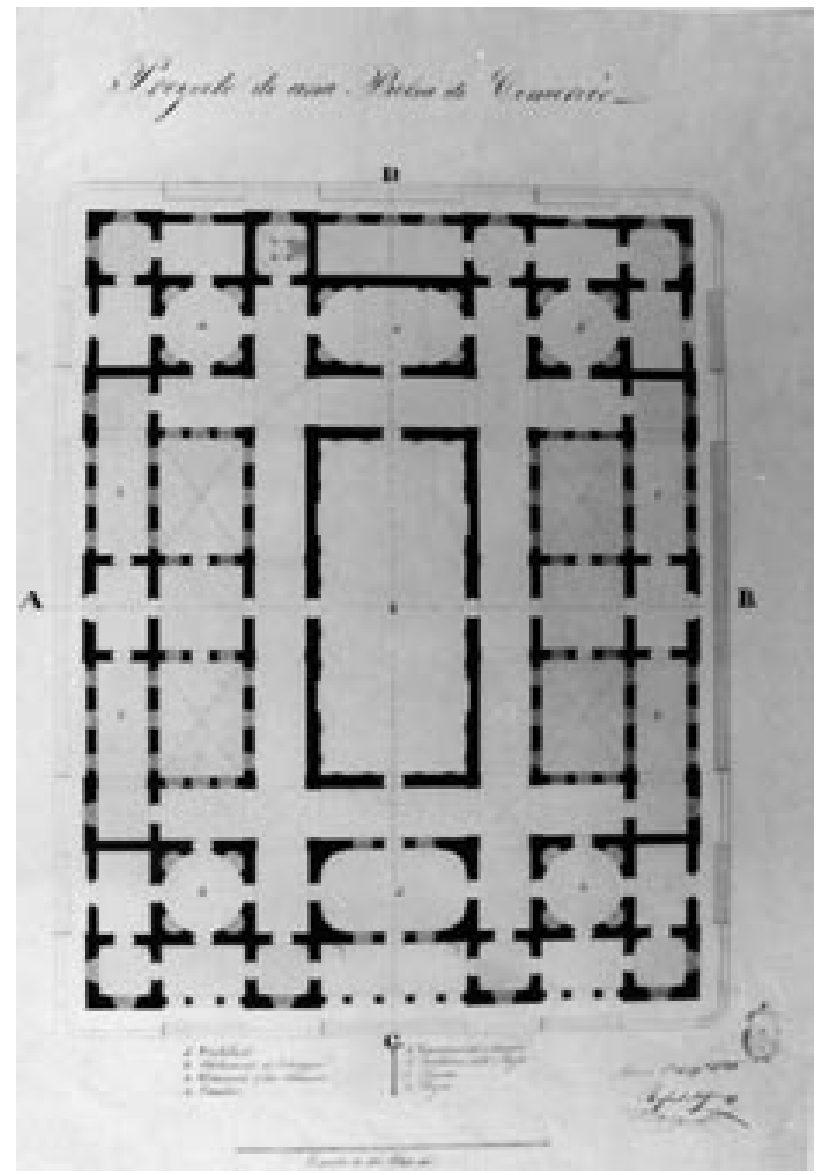

26. Planta para una bolsa de comercio, 17 de septiembre de 1835 ¿Primer examen de ingreso? (A.A.S.F.) 


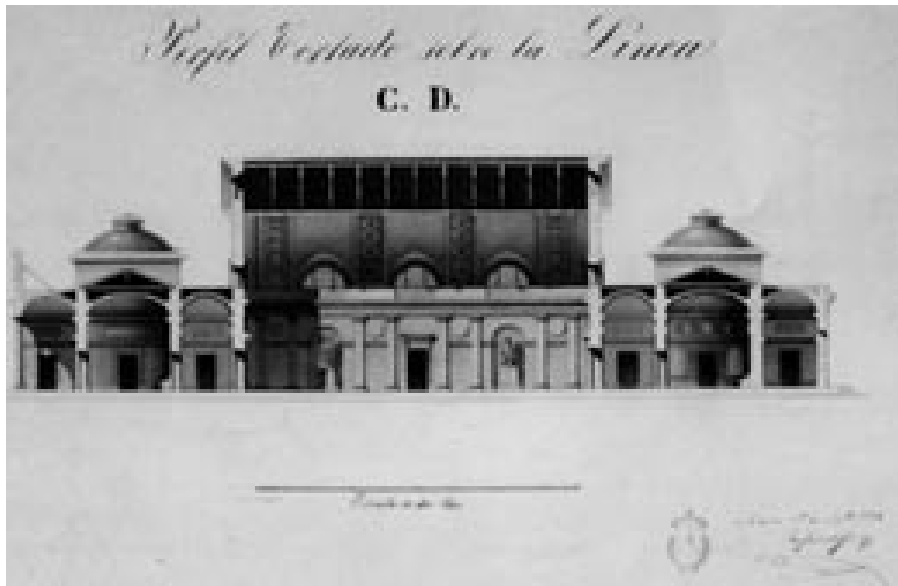

27. Proyecto para una bolsa de comercio en estilo clasico. Sección longitudinal (A.A.S.F.)

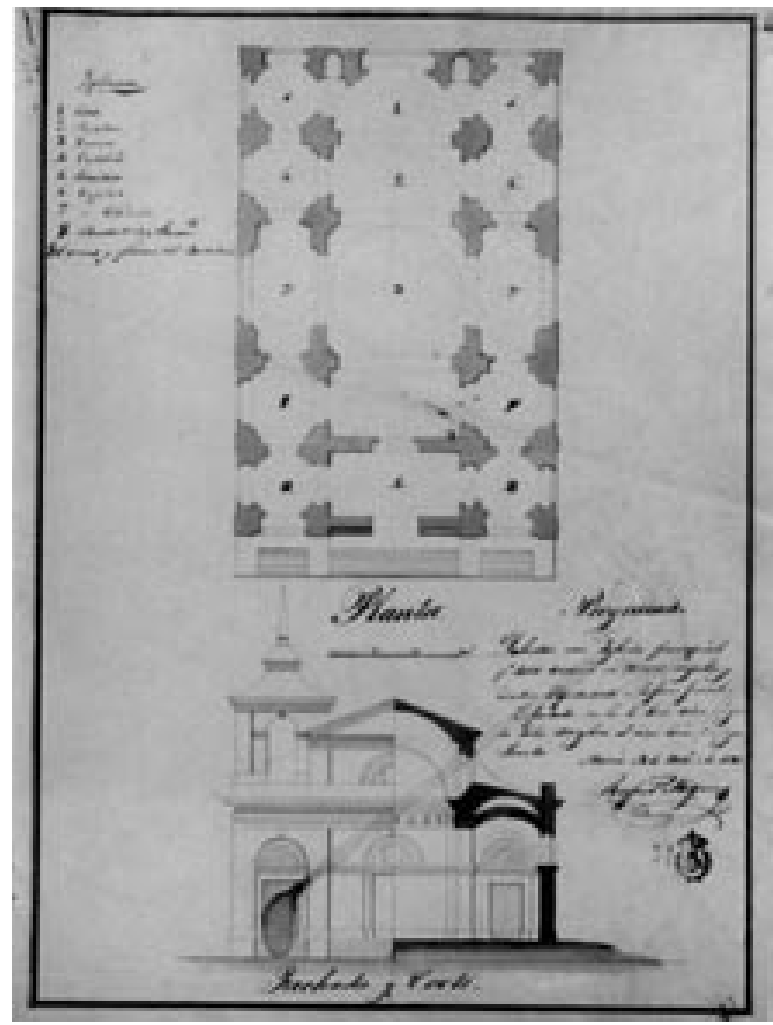

28. Planta y sección de una iglesia parroquial. Examen para la obtención del título de arquitecto, 13 de noviembre de 1835. (A.A.S.F.) 